\title{
The Periaqueductal Gray Orchestrates Sensory and Motor Circuits at Multiple Levels of the Neuraxis
}

\author{
Stella Koutsikou, ${ }^{1,2 \star}$ Thomas C. Watson, ${ }^{1,3,4,5 *}$ Jonathan J. Crook, ${ }^{1}$ J. Lianne Leith, ${ }^{1}$ Charlotte L. Lawrenson, ${ }^{1}$ \\ Richard Apps, ${ }^{1 \dagger}$ and ${ }^{\circ}$ Bridget M. Lumb ${ }^{1 \dagger}$ \\ ${ }^{1}$ School of Physiology, Pharmacology, and Neuroscience, and ${ }^{2}$ School of Biological Sciences, University of Bristol, Bristol BS8 1TQ, United Kingdom, \\ ${ }^{3}$ Neuroscience Paris Seine, Cerebellum, Navigation and Memory Team, Sorbonne Universities, Université Pierre et Marie Curie, University of Paris 06 Unité \\ Mixte de Recherche Scientifique 8246, ${ }^{4}$ INSERM Unité Mixte de Recherche Scientifique 1130, and ${ }^{5}$ Centre National de la Recherche Scientifique Unité Mixte \\ de Recherche 8246, F-75005 Paris, France
}

The periaqueductal gray (PAG) coordinates behaviors essential to survival, including striking changes in movement and posture (e.g., escape behaviors in response to noxious stimuli vs freezing in response to fear-evoking stimuli). However, the neural circuits underlying the expression of these behaviors remain poorly understood. We demonstrate in vivo in rats that activation of the ventrolateral PAG (vlPAG) affects motor systems at multiple levels of the neuraxis through the following: (1) differential control of spinal neurons that forward sensory information to the cerebellum via spino-olivo-cerebellar pathways (nociceptive signals are reduced while proprioceptive signals are enhanced); (2) alterations in cerebellar nuclear output as revealed by changes in expression of Fos-like immunoreactivity; and (3) regulation of spinal reflex circuits, as shown by an increase in $\alpha$-motoneuron excitability. The capacity to coordinate sensory and motor functions is demonstrated in awake, behaving rats, in which natural activation of the vlPAG in fear-conditioned animals reduced transmission in spino-olivo-cerebellar pathways during periods of freezing that were associated with increased muscle tone and thus motor outflow. The increase in spinal motor reflex excitability and reduction in transmission of ascending sensory signals via spinoolivo-cerebellar pathways occurred simultaneously. We suggest that the interactions revealed in the present study between the vlPAG and sensorimotor circuits could form the neural substrate for survival behaviors associated with vlPAG activation.

Key words: cerebellum; fear; nociception; periaqueductal grey; proprioception; spinal cord

\section{Significance Statement}

Neural circuits that coordinate survival behaviors remain poorly understood. We demonstrate in rats that the periaqueductal gray (PAG) affects motor systems at the following multiple levels of the neuraxis: (1) through altering transmission in spino-olivary pathways that forward sensory signals to the cerebellum, reducing and enhancing transmission of nociceptive and proprioceptive information, respectively; (2) by alterations in cerebellar output; and (3) through enhancement of spinal motor reflex pathways. The sensory and motor effects occurred at the same time and were present in both anesthetized animals and behavioral experiments in which fear conditioning naturally activated the PAG. The results provide insights into the neural circuits that enable an animal to be ready and able to react to danger, thus assisting in survival.

\section{Introduction}

The ability to interact with challenging environments requires detection of salient signals that ultimately drive appropriate mo-

Received Jan. 20, 2015; revised Aug. 20, 2015; accepted Aug. 21, 2015.

Author contributions: S.K., R.A., and B.M.L. designed research; S.K., T.C.W., J.J.C., J.L.L., and C.L.L. performed research; S.K., T.C.W., J.J.C., and J.L.L. analyzed data; S.K., T.C.W., J.J.C., R.A., and B.M.L. wrote the paper.

This work was supported by the Biotechnology and Biological Sciences Research Council UK and the Medical Research Council. We thank Rachel Bissett, Barbara Carruthers, Nuria Berástegui, and Derek Carr for technical assistance.

The authors declare no competing financial interests.

*S.K. and T.C.W. are co-first authors.

${ }^{\dagger}$ R.A. and B.M.L. are co-senior authors. tor behaviors. These include defense behaviors such as fear-evoked freezing, which are dependent on the integrity of the periaqueductal gray (PAG) and orchestrated by neurons in its ventrolateral sector (vlPAG) (LeDoux et al., 1988; Carrive et al., 1997; LeDoux, 2012).
This article is freely available online through the J Neurosci Author Open Choice option.

Correspondence should be addressed to Prof. Richard Apps, School of Physiology, Pharmacology, and Neuroscience, Medical Sciences Building, University of Bristol, University Walk, Bristol BS8 1TD, UK. E-mail: R.Apps@bristol.ac.uk.

DOI:10.1523/JNEUROSCI.0261-15.2015

Copyright $\odot 2015$ Koutsikou, Watson et al.

This is an Open Access article distributed under the terms of the Creative Commons Attribution License Creative Commons Attribution 4.0 International, which permits unrestricted use, distribution and reproduction in any medium provided that the original work is properly attributed. 
Neural substrates that underlie requisite alterations in autonomic functions (e.g., cardiorespiratory adjustments) and sensory processing (e.g., modulation of pain processing) that accompany defense are well understood (Lovick and Bandler, 2005); however, little is known of the neural circuits that mediate the characteristic motor responses associated with vlPAG activation.

We recently reported that activation of the vlPAG causes an increase in $\alpha$-motoneuronal excitability, which is thought to support freezing behavior (Koutsikou et al., 2014). Defense behaviors also require that an animal's response is not perturbed from essential motor activity, as would be caused by salient sensory information modifying activity in supraspinal motor systems, leading to changes in behavior. Indeed, our initial investigations (Cerminara et al., 2009) revealed that activation of the vlPAG can significantly decrease cerebellar climbing fiber (CF) field potentials evoked by stimulation of the hindlimb, indicating a reduction of CF activation by afferent systems.

CFs are generally thought to act as "teaching" signals important for cerebellar cortical plasticity (Ito, 2001). Reduction of transmission in ascending CF pathways might therefore allow only behaviorally relevant training signals to be forwarded to the cerebellum. Conversely, the timing hypothesis proposes that CFs have a more direct influence on movement: their activation is thought to be capable of controlling patterns of synchronous activity in the cerebellum that underlie motor coordination (Llinás, 2011). In relation to the latter, our findings raise the possibility that the vlPAG has the capacity to protect patterns of motor outflow in emergency situations by gating distracting sensory inputs to cerebellar circuits that might otherwise perturb requisite behavior.

To examine the nature and extent of modulatory influences of the vlPAG on different qualities of sensory input to cerebellar circuits, the present study recorded spino-olivary neurons to determine any differential effects on innocuous (somatosensory and proprioceptive) versus nociceptive transmission relayed via spino-olivocerebellar pathways. Complementary functional anatomical studies also tested effects of the vlPAG on nociceptor-evoked responses of cerebellar output circuits as assessed by the expression of Fos-like immunoreactivity (FLI) in the cerebellar nuclei.

To examine the effects of vlPAG modulation on spinal motor circuits, two further series of experiments were performed, one in anesthetized and one in awake animals, in which effects of vlPAG activation were tested on spinal motor circuit excitability and freezing behavior, respectively. An additional functionally pertinent question is whether localized pools of neurons in the vlPAG control both motor outflow and sensory transmission at the same time. To address this, spinal reflex and peripherally evoked CF responses were recorded simultaneously.

Overall, the results demonstrate that the vlPAG has the capacity to orchestrate processing of sensory signals and motor output that together most likely underlie context-dependent defensive responses such as fear-evoked freezing behavior.

\section{Materials and Methods}

\section{Procedures}

All animal procedures were performed in accordance with the UK Animals (Scientific Procedures) Act of 1986 and associated guidelines.

\section{Experiments in anesthetized animals}

Recording of dorsal horn neuronal activity. Experiments were performed on 26 adult male Wistar rats weighing 290-320 g and housed in standard conditions. Anesthesia was induced with $2.5 \%$ halothane (Merial) in $\mathrm{O}_{2}$ and maintained by constant intravenous (jugular vein) infusion of $\alpha$ xalone (30-40 mg/kg/h; Vétoquinol) and maintained at a level at which there were no substantial changes in blood pressure (measured via the carotid artery) in response to a firm pinch of the forepaw. The trachea was cannulated to ensure patency of the respiratory tract and for artificial ventilation when required. Arterial blood pressure and rectal temperature were monitored and maintained within physiological limits. All animals were positioned in a stereotaxic frame and a craniotomy was performed to allow access to the vlPAG $(7.6-8.5 \mathrm{~mm}$ caudal from bregma, $0.8-1.0 \mathrm{~mm}$ lateral to the midline, and $\sim 5.3 \mathrm{~mm}$ deep to the cortical surface (Paxinos and Watson, 2005).

A laminectomy was performed between T11 and T13 to record from spinal dorsal horn neurons in laminae I-V between lumbar segments L3 and L5. The vertebral column was clamped at each end of the laminectomy to increase stability during neuronal recordings. The dura was removed from the surface of the spinal cord, a pool was made with the skin flaps, and the whole area was filled with warm agar. Once the agar was set, a small window was cut out over the desired recording site of the spinal cord and filled with warm paraffin oil. A glass-coated tungsten microelectrode (Merrill and Ainsworth, 1972) was lowered into the cord. Singleunit neuronal activity was amplified $(\times 10 \mathrm{k})$ and filtered $(500 \mathrm{~Hz}-10 \mathrm{kHz}$; NeuroLog System; Digitimer) before being captured at $10 \mathrm{k} / \mathrm{samples} / \mathrm{s}$ via a 1401plus (CED) onto a PC running Spike2 software (CED).

Antidromic testing of spinal neurons for a supraspinal projection. Dorsal horn neurons ( $n=39$ from 26 rats) were tested for a supraspinal projection to the caudal brainstem. Supraspinal projection neurons were identified by their antidromic responses to electrical stimulation in the vicinity of the contralateral inferior olive (IO) complex. A craniotomy was performed to allow access to the contralateral IO $(\sim 12.5 \mathrm{~mm}$ caudal to bregma, $1.2-1.5 \mathrm{~mm}$ lateral to the midline, and $8.5-9.0 \mathrm{~mm}$ deep to the cortical surface according to the brain atlas of Paxinos and Watson, 2005), with a bipolar stimulating electrode (interpolar distance of 0.5 $\mathrm{mm}$; SNE-100X; Harvard Apparatus). Single square pulses (20-100 $\mu \mathrm{A}$, $0.1 \mathrm{~ms}$ duration at a rate of $0.1 \mathrm{~Hz}$ ) were delivered via the stimulating electrode and dorsal horn neurons were classified as projection neurons if their action potentials met the following standard criteria for antidromic activation (see Fig. 1a): (1) constant latency, (2) frequency following to three stimuli delivered at a rate of $200 \mathrm{~Hz}$, and (3) collision of the antidromic spike with a spontaneous or evoked orthodromic spike (Fuller and Schlag, 1976; Lipski, 1981).

The possibility that electrical stimulation within the IO may have excited ascending fibers that lie outside or course through the IO was minimized by positioning the IO stimulating electrode at a depth where the minimum current was required to evoke an antidromic spike (see Fig. 1b). In support of this, Molinari and Dostrovsky (1987) showed that stimulus currents at a comparable intensity spread only minimally beyond the borders of IO and failed to activate axons of the medial lemniscus adjacent to the dorsal accessory olive (DAO). In the present study, we aimed to confirm histologically as many IO stimulation sites as possible (see Fig. 1d). By adopting these approaches, it therefore seems reasonable to assume that the IO was the main if not exclusive target of spinal projection neurons identified in this study and the term "spino-olivary" is used accordingly.

Functional classification of spino-olivary neurons. Once units were identified as projecting to IO, the peripheral receptive field was characterized using natural mechanical stimuli: low-threshold (light brush, tap, gentle pressure, joint movement) and high-threshold (pinch with hand-held forceps). According to their response properties, the spino-olivary units were classified into one of four groups as described by Menétrey et al. (1977): class 1 (low-threshold; innocuous), class 2 (low- and high-threshold; wide dynamic range), class 3 (high-threshold; nociceptive-specific), and class 4 (joint movement and deep muscle pressure; proprioceptive). Responses to innocuous and noxious stimuli were quantified by counting the total number of spikes evoked during application of the stimulus and then subtracting spontaneous activity of the neuron, measured for a similar time window before the stimulus.

Neuronal activation of the vlPAG. Glass micropipettes were advanced into the caudal vlPAG under stereotaxic guidance (Paxinos and Watson, 2005). Micropipettes were filled with $50 \mathrm{~mm}$ the excitatory amino acid DL-homocysteic acid (DLH; Sigma-Aldrich) mixed with pontamine sky blue dye to mark the injection sites (McMullan and Lumb, 2006a, 2006b; 
Koutsikou et al., 2007). Pressure injections of DLH (60-80 nl) typically evoked decreases in mean arterial pressure. Subsequently, descending influences from the vlPAG were tested, first on the responses of spinoolivary neurons to natural peripheral stimulation, and, in a different series of experiments, on H-reflex and cerebellar field potential amplitudes (see detailed methods below).

Experimental protocol of descending modulation of spino-olivary neuronal activity. A pneumatic pincher was used to deliver mechanical stimuli ( $15 \mathrm{~s}$ duration; innocuous $0.5 \mathrm{~N}$ and/or noxious $3.6 \mathrm{~N}$ ) every 5 min to the receptive fields of class 1-3 spino-olivary neurons. After three baseline responses were obtained from each unit, a microinjection of DLH was made into the vlPAG 5-10 s before the onset of the next pinch stimulus. Three additional cycles of pinch stimulation were then repeated to monitor recovery from any descending influences. Only the last $10 \mathrm{~s}$ of each response to noxious pinch was analyzed because the initial $5 \mathrm{~s}$ was presumed to contain a considerable amount of low-threshold, rapidly adapting activity (Hartell and Headley, 1990). In this and previous studies (McMullan and Lumb, 2006b; Leith et al., 2010), consistency of responses indicate that repeated noxious stimuli (limited to 7 stimuli per animal) at $5 \mathrm{~min}$ intervals does not result in tissue damage and/or hyperalgesia.

For responses evoked by innocuous mechanical stimuli, only the first $5 \mathrm{~s}$ of the spike activity were analyzed. Spontaneous activity measured 5 or $10 \mathrm{~s}$ before the onset of the stimulus was subtracted from responses to innocuous and noxious stimuli, respectively. Responses of class 4 spinoolivary neurons were elicited by manual full ankle joint rotation (class 4 neurons did not fire in response to touch of the hindpaw) of the ipsilateral hindlimb for $10 \mathrm{~s}$ every $3 \mathrm{~min}$. After three baseline responses were obtained, microinjection of DLH was made into the vlPAG $\sim 5-10 \mathrm{~s}$ before the onset of the next joint rotation/manipulation. The spike count of the entire $10 \mathrm{~s}$ duration response was corrected for spontaneous activity of the cell measured over $10 \mathrm{~s}$ before the onset of the stimulus and responses were then analyzed to test for any effects of descending control.

Histology. At the end of every experiment, positive DC current was applied through the stimulating electrode to create lesions that were recovered postmortem to establish electrode tip positions (see Fig. 1d). Animals were killed with an overdose of sodium pentobarbitone (intravenous) and, after perfusion and fixation, the brain tissue was removed and postfixed for $24 \mathrm{~h}$ in $4 \%$ phosphate-buffered paraformaldehyde solution. The tissue was then transferred to $30 \%$ sucrose for at least $24 \mathrm{~h}$. Coronal sections $(50 \mu \mathrm{m})$ of the midbrain and medulla were cut on a freezing microtome for histological verification of pontamine sky blue injection sites and electrolytic lesions, marking stimulating electrode loci in the PAG and IO, respectively.

Fos immunohistochemistry. Experiments were performed on 32 adult male Wistar rats weighing 250-350 g. Anesthesia was induced using halothane $\left(2.5 \%\right.$ in $\mathrm{O}_{2}$; Merial) and, after preparatory surgery, was maintained by continuous intravenous infusion of alfaxalone $(30-40 \mathrm{mg} /$ $\mathrm{kg} / \mathrm{h}$; Vétoquinol). Body temperature was monitored and maintained at $37.0 \pm 0.5^{\circ} \mathrm{C}$ and venous, arterial, and tracheal cannulations allowed anesthetic administration, monitoring of arterial blood pressure, and patency of the respiratory tract, respectively. In some experiments, the head was fixed in a stereotaxic frame (nose clamp and ear bars) and a small craniotomy performed to allow access to the midbrain with glass pipettes. After the preparatory surgery, animals were allowed to stabilize for a minimum period of $2 \mathrm{~h}$.

Anesthetic control group. Animals were cannulated and maintained as described above for $4 \mathrm{~h}$. One anesthetic control group consisted of rats in which the jugular vein, carotid artery, and trachea were cannulated $(n=4)$. In a second anesthetic control group $(n=4)$, only the jugular vein was cannulated. There was no significant difference between these two groups (Kruskall-Wallis test), so the data were pooled $(n=8)$.

PAG experimental group. The PAG was chemically stimulated as described above for the acute electrophysiological experiments. Changes (decreases) in blood pressure evoked by injection of DLH were recorded and helped to confirm that injection sites were in the vlPAG. Saline control animals received an equivalent volume of saline containing pontamine sky blue dye $(60-80 \mathrm{nl})$. Three injections of DLH $(n=7)$ or saline $(n=7)$ were delivered at 10 min intervals. The animals were then main- tained under anesthesia for a further $2 \mathrm{~h}$, timed from the second of the three injections, to allow for expression of Fos protein in supraspinal structures (Koutsikou et al., 2007).

Noxious pinch group. In six alfaxalone-anesthetized animals, noxious stimuli were applied to the snout using hand-held large rat-toothed forceps (three $20 \mathrm{~s}$ pinches at intervals of $10 \mathrm{~min}$ ). Animals were then maintained under anesthesia for a further $2 \mathrm{~h}$ to allow time for the expression of Fos protein.

Sodium nitroprusside group. To control for blood pressure effects, in four alfaxalone-anesthetized animals, three intravenous injections of sodium nitroprusside $(100 \mathrm{ng} / \mathrm{ml})$ were administered at intervals of $10 \mathrm{~min}$. Animals were then maintained under anesthesia for a further $2 \mathrm{~h}$, timed from the second injection, to allow time for the expression of Fos protein.

Tissue processing. At the end of every Fos experiment, animals were overdosed with anesthetic and perfused as described previously for electrophysiological experiments. Coronal sections $(60 \mu \mathrm{m})$ of the midbrain were cut, collected in $0.01 \mathrm{~m}$ phosphate buffer, mounted on gelatinized slides, and then viewed under a Zeiss Axioskop 2+ microscope. The injection sites were identified by the location of the dye spread and pipette track, with reference to a stereotaxic atlas (Paxinos and Watson, 2005). Staining for FLI in the cerebellum was performed using previously described methods (Koutsikou et al., 2007).

In brief, transverse sections ( $40 \mu \mathrm{m})$ of cerebella embedded in gelatin were cut on a freezing microtome. Every third section was processed free floating for FLI using a polyclonal rabbit Fos antibody (Santa Cruz Biotechnology; 1:5000 in $0.1 \mathrm{M}$ phosphate buffer containing $1 \%$ bovine serum albumin, $0.1 \%$ Triton X-100, and $0.01 \%$ sodium azide) for $48-72 \mathrm{~h}$ at $4^{\circ} \mathrm{C}$. Incubation in secondary biotinylated anti-rabbit antibody IgG [Sigma-Aldrich; 1:500 in $0.01 \mathrm{~m}$ PBS with $0.1 \%$ Triton X-100 (PBS-T)] was performed for $1-2 \mathrm{~h}$ at room temperature $\left(20^{\circ} \mathrm{C}\right)$. The sections were subsequently incubated in extravidin peroxidase (Sigma-Aldrich; 1:1000 in PBS-T) for $1-2 \mathrm{~h}$ and the peroxidase visualized using 3,3-diaminobenzidine (0.015\%; Sigma-Aldrich) and glucose oxidase (Sigma-Aldrich). Finally, all sections were mounted onto gelatinized slides. A number of sections from each series were processed in the absence of primary antibody to serve as negative controls.

FLI microscopy and mapping. Immunologically processed sections were viewed under a $20 \times$ or $40 \times$ objective to identify FLI-labeled cells. Cells were counted as labeled if they displayed staining only in the nucleus with a clear contrast to the background staining in the immediate area (Hunt et al., 1987). A bright nucleolus was often visible. FLI-labeled cells were counted visually and mapped onto standard coronal maps of the cerebellar nuclei adapted from Ruigrok and Voogd (1990, 2000). Because most FLI labeling was in the medial cerebellar nucleus (see Results), quantitative analysis of FLI-positive neurons was confined to its three subdivisions. No difficulty was found in assigning cell labeling to the different subdivisions of the medial nucleus on standard maps (Buisseret-Delmas, 1988; Buisseret-Delmas and Angaut, 1993). No significant differences in FLI were observed between ipsilateral and contralateral regions in any of the groups $(p>0.05$, permutation paired $t$ test, see following section). FLI counts from cerebellar nuclear subdivisions on both sides were therefore pooled for quantitative analysis.

Preliminary experiments sought to investigate the effects of vlPAG activation on the IO. However, in the absence of peripheral stimulation, background FLI in the IO was highly variable and precluded reliable investigation of the effects of PAG stimulation.

Neuroanatomical statistical analysis. In some cases, no FLI neurons were observed in some subdivisions of the medial cerebellar nucleus. For this reason, a permutation one-way ANOVA followed by post hoc permutation $t$ tests with Bonferroni's correction was used to test for significant differences between groups. For these statistical tests, the test statistic generated for the observed data is compared with test statistics generated for random "resampling" of the original data. A permutation $p$-value is calculated by observing the proportion of permutations that returned a test statistic greater than or equal to the original test statistic. All permutation tests were based upon $1,000,000$ permutations (LaFleur and Greevy, 2009). Statistical analysis was performed with Rundom Pro version 3.14. For all statistical tests, the threshold for significance was defined as $p<0.05$. 
$H$-reflex recordings. In five animals, a pair of stimulating needle electrodes (25 G) was inserted subcutaneously between the Achilles tendon and the distal tibial nerve of the left hindlimb (Gozariu et al., 1998; Koutsikou et al., 2014). Constant current $50 \mu$ s square wave pulses were delivered at $3 \mathrm{~s}$ intervals. A pair of intramuscular stainless steel recording electrodes $(0.075 \mathrm{~mm}$ in diameter Teflon-coated; Advent Research Materials) was inserted into the ipsilateral plantaris muscle to record evoked EMG activity (M-wave and $\mathrm{H}$-reflex) in response to low-intensity electrical stimulation of the nerve (Mattsson et al., 1984; Gozariu et al., 1998).

The stimulus intensity was adjusted so that it was submaximal for evoking an H-reflex response and the amplitude of the H-reflex was always larger than the $\mathrm{M}$-wave. The responses were amplified $(\times 2 \mathrm{k})$ and filtered ( $50 \mathrm{~Hz}$ to $5 \mathrm{kHz}$; Neurolog System, Digitimer) before being captured via a 1401 plus A/D device (CED). The individual H-reflex and $\mathrm{M}$-wave peak-to-peak amplitudes evoked by each stimulus were measured using Spike2 software (CED). M-wave and $\mathrm{H}$-reflex responses were recorded before and after microinjection $(60-80 \mathrm{nl})$ of DLH $(50 \mathrm{~mm}$; Sigma-Aldrich) into the vlPAG. The mean of five responses in each of the following periods were averaged and statistically compared to determine any influence of the vlPAG on H-reflex amplitude: prior (pre-PAG), immediately after: PAG, and $10 \mathrm{~min}$ after DLH microinjections (postPAG). In all cases, the H-reflex data were normalized with respect to the $\mathrm{M}$-wave. The latter serves as a useful internal control of the constancy of the peripheral nerve stimulation. Note also that previous studies have shown that the cerebellum does not have a tonic influence on H-reflex excitability (Chen and Wolpaw, 2005).

Recording of cerebellar cortical field potentials. Simultaneous with recordings of H-reflexes, in the same five rats described in the previous section, cerebellar field potentials were recorded from the cortical surface of the copula pyramidis after exposure of the dorsal surface of the posterior lobe of the cerebellum. A low-impedance silver wire ball electrode was used to record extracellular field potentials in response to constant current $50 \mu$ s square wave pulses that were delivered at 3 s intervals to the tibial nerve (further details above). Cerebellar responses were recorded differentially between the ball electrode and an indifferent $(\mathrm{Ag}-\mathrm{AgCl}$ disc) placed in the bone margin lateral to the cerebellar exposure. Responses were amplified and filtered $(30 \mathrm{~Hz}$ to $2.5 \mathrm{kHz}$; Neurolog System; Digitimer), with any $50 \mathrm{~Hz}$ electrical interference removed by a Humbug device (QuestScientific distributed by Digitimer). The signal was sampled at $20 \mathrm{kHz}$ using a CED 1401plus A/D converter and recorded using Spike2 software (CED). Responses were analyzed offline: the amplitude and latency to onset of the initial rising phase of individual evoked field potentials was measured using Spike2 software.

Experimental protocol to evoke simultaneous descending modulation of the H-reflex and electrically evoked cerebellar field potentials. Peak-to-peak amplitude measurements of $\mathrm{M}$-wave (internal control), H-reflex, and cerebellar field potentials were made before and after microinjections of DLH into the vlPAG. The mean response prior (pre-PAG), immediately after (PAG), and 2-10 min after DLH (post-PAG) microinjection were averaged and compared statistically to determine any descending influences on the peak-to-peak amplitudes.

Histology. At the end of every experiment, animals were killed with an overdose of sodium pentobarbitone (intravenous). The brains were removed and fixed for $24 \mathrm{~h}$ in $4 \%$ phosphate-buffered paraformaldehyde solution. The tissue was then transferred to $30 \%$ sucrose for at least $24 \mathrm{~h}$. Coronal sections $(50 \mu \mathrm{m})$ of the midbrain were cut on a freezing microtome for histological verification of pontamine sky blue injection sites in the PAG.

\section{Experiments in awake animals}

Implant procedures. Under sodium pentobarbital anesthesia $(60 \mathrm{mg} / \mathrm{kg}$, i.p.), a total of 14 adult male Wistar rats (300-400 g; Charles River Laboratories) were implanted with an in-house-built miniature microdrive carrying up to four independently movable electrodes $(12.5 \mu \mathrm{m}$ tungsten wire, California Fine Wire or $75 \mu$ m epoxy coated stainless steel, FHC; impedance $100-200 \mathrm{kOhms}$ at $1 \mathrm{kHz}$ ). The microdrive was positioned over the cerebellum (AP-12 mm, ML $0.9 \mathrm{~mm}$ relative from bregma). Optimal recording position within the cerebellar cortex was determined by physiological recordings made during surgery (to identify the cerebellar site where ipsilateral hindlimb stimulation evoked the largest extracellular field potential; $\sim 4 \mathrm{~mm}$ from brain surface). Pairs of flexible, stainless steel wires (Cooner Wire) were sutured into the neck muscles (Steenland and Zhuo, 2009) and used as EMG recording electrodes. Bipolar stimulating wires (Cooner Wire) were sutured subcutaneously within the hindlimb (superficially and in close proximity to the ankle joint) ipsilateral to the cerebellar recording electrodes. All leads were fed subcutaneously to connectors within the headpiece (Pardoe et al., 2004). After surgery, animals were housed under normal environmental conditions $\left(\sim 20^{\circ} \mathrm{C}\right.$ and $45-65 \%$ humidity) on a $12 \mathrm{~h}$ dark-light cycle and provided with food and water ad libitum.

Awake animal recording. After recovery from surgery, differential recordings were made using a Lynx 8 system (Neuralynx), CED 1401 A/D device and Spike2 acquisition software (CED). A skull screw above the cerebellum served as the reference for cerebellar field potential (CFP) signals. EMG recordings from either side of the neck were referenced against each other in a bipolar manner. Both EMG and CFP signals were sampled at $5 \mathrm{kHz}$ and filtered from $0.1 \mathrm{~Hz}$ to $1 \mathrm{kHz}$. Single-unit activity was sampled at $25 \mathrm{kHz}$ and filtered from $300 \mathrm{~Hz}$ to $6 \mathrm{kHz}$. Video recordings were made throughout the experiments using a webcam (30 frames/s capture rate) and synchronized with electrophysiological data in Spike2 software.

Hindimb stimulation. Electrical stimuli were applied via the peripherally implanted stimulating wires (square pulses of $0.2 \mathrm{~ms}$ duration; constant current). During paired pulse experiments, stimuli were applied at varying time intervals (from 30 to $90 \mathrm{~ms}$ ). During fear tests, stimuli were typically applied every $1.5 \mathrm{~s}$ at $1.5 \times$ the threshold to evoke a CFP (Pardoe et al., 2004). This intensity of stimulus typically evoked a mild twitch of the stimulated hindlimb, but otherwise did not appear to disturb the animal.

Fear conditioning. Fear conditioning $(n=5)$ and testing for freezing (see below) took place in two different contexts (A and B, respectively). The Skinner box (Med Associates) and its floor were cleaned thoroughly with $70 \%$ ethanol after every session. On days $1-3$, animals were acclimatized for 5 min each day to context $\mathrm{A}$. On day 4 , in context $\mathrm{A}$, rats were exposed to an auditory cue (conditioned stimulus, CS) or a foot shock (unconditioned stimulus, US; $0.75 \mathrm{~mA}$ ) fear-conditioned protocol. This involved 7 trials ( $30 \mathrm{~s}$ intertrial interval) of paired CS ( $1 \mathrm{kHz}$ auditory tone, $75 \mathrm{~dB}, 10 \mathrm{~s}$ duration) and US presentations (Sacchetti et al., 2004). Due to stimulus and movement artifacts, it was not possible to record electrophysiological responses during fear conditioning.

Fear-conditioned testing. Twenty-four hours after fear conditioning, each animal $(n=5)$ was placed in the Skinner box with context $\mathrm{B}$ and, after $5 \mathrm{~min}$, they were presented with $7 \times \mathrm{CS}$. Freezing epochs were identified using a combination of neck EMG recordings (Steenland and Zhuo, 2009) and video recordings. Freezing was confirmed by cessation of all movements except those associated with respiration and eye movements and was typically characterized by crouching postures (Blanchard and Blanchard, 1969). CFPs were evoked at regular intervals (every $1.5 \mathrm{~s}$, see above) and neck EMG recorded continuously throughout fear retrieval.

Chemical activation of vlPAG. In one animal, a bilateral injection cannula (Plastics One) was implanted stereotaxically into the vlPAG $\left(10^{\circ}\right.$ angle, AP $-2.2 \mathrm{~mm}$, ML $1 \mathrm{~mm}$ from bregma, $5.5 \mathrm{~mm}$ deep from brain surface). The vlPAG was chemically activated using $100 \mathrm{nl}$ of $50 \mathrm{~mm}$ DLH (Sigma-Aldrich) containing pontamine sky blue, which was pressure injected via the cannula while the animal was sitting quietly at rest in its home cage. Evoked CFPs and neck EMG were recorded as indicated above before, during, and after the DLH injection.

Histology for chronic recording experiments. At the end of each chronic recording experiment, animals were overdosed and perfused as described above for experiments in acutely anesthetized animals. Before perfusion, positive DC current was applied through the recording electrodes to create lesions that were recovered postmortem to establish electrode tip positions (see Fig. 5). Cerebellar sagittal sections $(50-80 \mu \mathrm{m})$ were processed in the same manner as for the nonrecovery experiments.

Analysis. Single unit neuronal activity, EMG, and evoked CFP amplitudes were displayed as mean \pm SEM. Evoked CFPs were detected and measured (peak-to-trough amplitude) using automated Spike2 scripts and then averaged across stimulation trials. Due to differences in field 
a

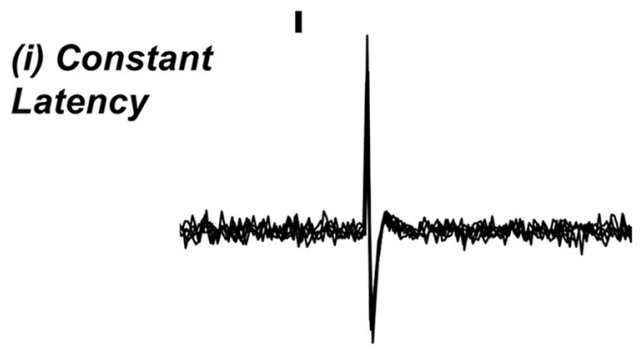

(ii) Following I I, I
Frequency

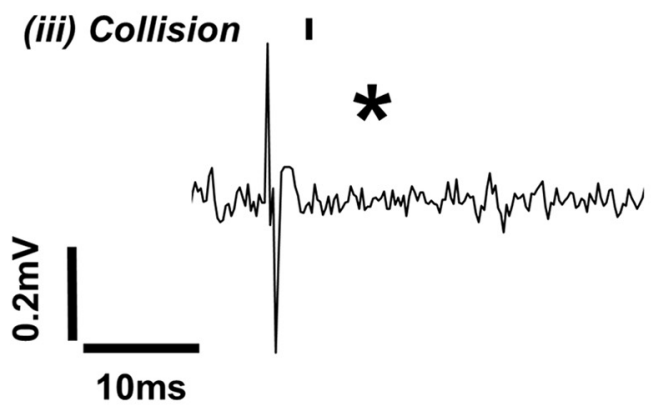

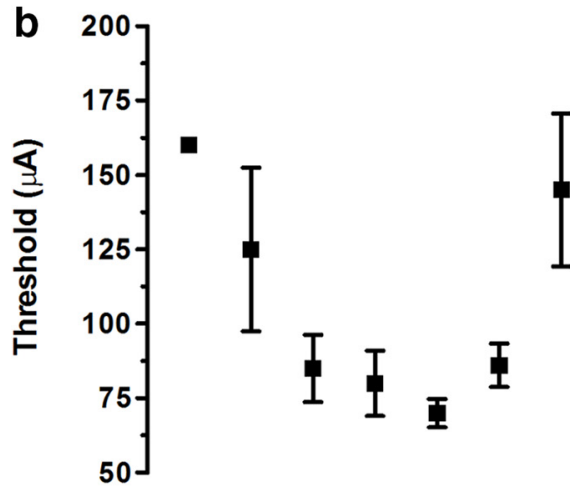
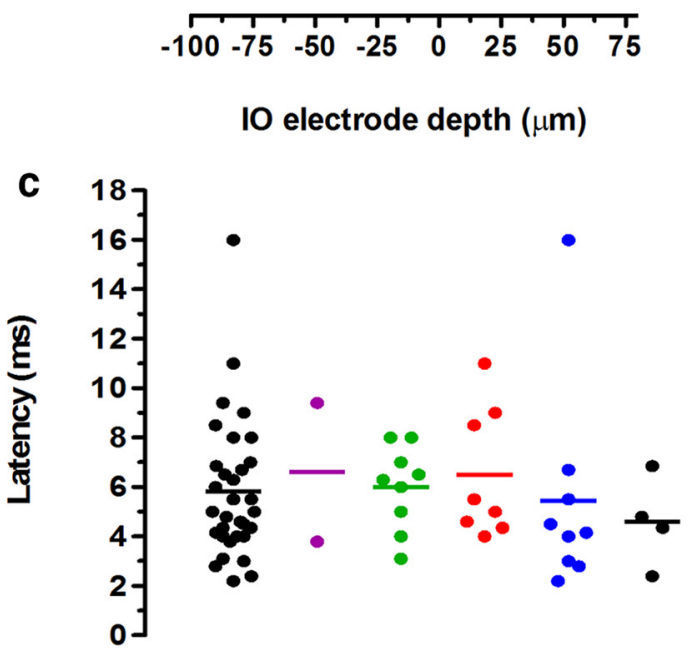

d

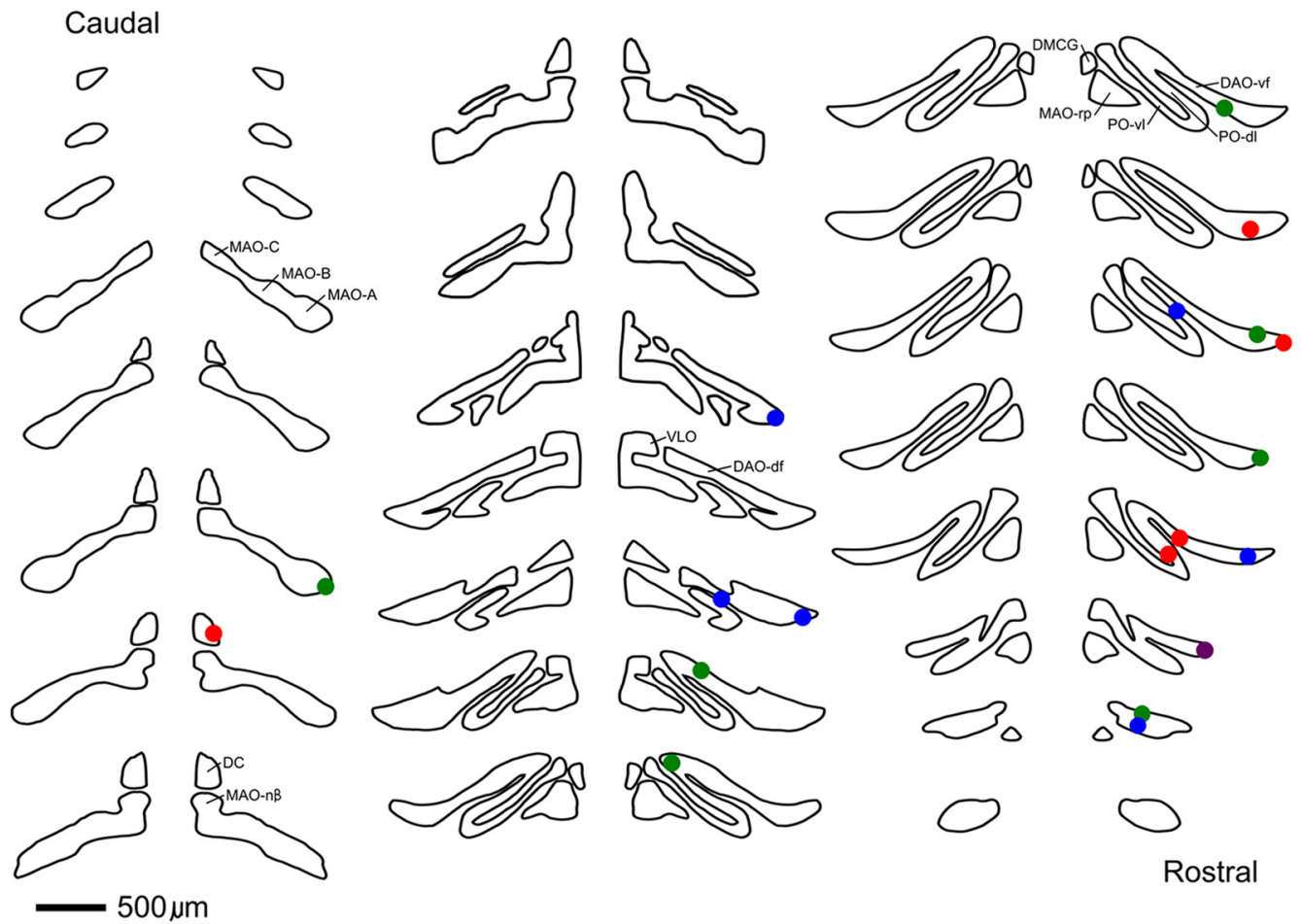

Figure 1. Characteristics of spino-olivary projection neurons. $\boldsymbol{a}$, Typical single case example of antidromic testing, demonstrating the following: (i) the constant latency of the antidromically evoked spike (five consecutive trials superimposed), (ii) the ability to follow high-frequency stimulation (200 Hz), and (iii) collision (asterisk) with an (Figure legend continues.) 
potential amplitude across animals (presumably due to variations in recording site position), pooled data were normalized by expressing mean response amplitude as a percentage of baseline amplitude. Freezing epochs were identified from rectified and smoothed $(0.025 \mathrm{~s})$ neck EMG recordings (Steenland and Zhuo, 2009) using custom scripts in Spike2 software. Neck EMG amplitude was compared during fear-conditioning experiments by sampling (one sample/s) the amplitude of rectified and smoothed EMG signal across the freezing and quiet rest epochs. Single unit activity was sorted using Spike2 template matching and principle component algorithms.

Electrophysiology statistical analysis. All statistical analysis was performed using Prism version 5.0 software (GraphPad). Physiological recordings from awake animals were compared statistically using paired or unpaired $t$ tests, one-way ANOVA (with Bonferroni's post test), and repeated-measures ANOVA (with Dunnett's post test) tests as appropriate. Responses after PAG activation were compared with pre-PAG and post-PAG responses using repeated-measures ANOVA (with Dunnett's post test). $p$-values $<0.05$ were considered to be statistically significant.

\section{Results}

\section{Characteristics of spino-olivary neurons}

Spino-olivary neurons were recorded to study influences of the vlPAG on ascending projections that influence supraspinal motor systems. Figure $1, a-c$, illustrates the identification and properties of spino-olivary neurons. Of our sample of dorsal horn neurons, 32 met all three standard criteria for antidromic activation (see Materials and Methods) and were selected for further analysis.

\section{Descending modulation of spino-olivary neuronal responses to innocuous and/or noxious stimuli}

All 32 dorsal horn neurons were classified by their responses to low- and high-threshold mechanical stimulation of their receptive field area on the ipsilateral hind leg (Fig. 1c) according to the scheme defined by Menétrey et al. (1977); class 1 (low-threshold, $n=2$ ), class 2 (wide dynamic range, $n=9$ ), class 3 (nociceptivespecific, $n=8$ ), and class 4 (proprioceptive, $n=9$ ). In addition, we recorded from spino-olivary projection neurons with unidentifiable receptive fields $(n=4)$. Histological identification of stimulating electrode loci was possible for 19 cells. Figure $1 d$ shows, on standard transverse outlines of the IO (Azizi and Woodward, 1987), that the majority of stimulation sites were in the rostral DAO (sites of antidromic activation of different classes of spino-olivary neurons as follows: purple, class 1 cells; green, class 2 cells; red, class 3 cells; and blue, class 4 cells).

To investigate descending control of sensory input to the olivocerebellar system, including any selectivity, we examined the effects of activation of vlPAG on responses of the different classes of spinoolivary projection neurons to noxious and non-noxious, including proprioceptive, stimulation (total $n=22$ neurons). The effects of neuronal activation of vlPAG are illustrated as single examples and as pooled data in Figure 2.

Clear differences were evident between the effects of descending control on the different classes of neurons with respect to

(Figure legend continued.) orthodromically evoked spike. $\boldsymbol{b}$, Mean \pm SEM of the thresholds $(n=5)$ for antidromic activation as a function of the position of the stimulating electrode in the 10 complex. Zero indicates the location of the stimulating electrode at a depth where the minimum current was required to evoke an antidromic spike. This location coincided stereotactically with the 10 and was confirmed histologically. c, Distribution of the antidromic activation latencies of all spino-olivary neurons according to receptive field class, including neurons with unidentified peripheral receptive field (No RF). $\boldsymbol{d}$, Histological identification of location of stimulation sites in the 10 (two sites were not recovered) plotted on standard transverse maps of the 10. MAO, Medial accessory olive; P0, principal olive; DC, dorsal cap; VLO, ventrolateral outgrowth. Purple indicates class 1; green, class 2; red, class 3; and blue, class 4. effects on their responses to innocuous and noxious stimuli, including responses to innocuous stimuli of different modality (innocuous pressure vs proprioceptive). These differences can be summarized as follows. For class 2 neurons $(n=7)$, chemical stimulation in the vlPAG significantly reduced, by an average of $51.6 \pm 8.9 \%$, their noxious pinch-evoked response $(p=0.011$, $F_{(2,37)}=5.15$, repeated-measures ANOVA followed by Dunnett's post test pre-PAG vs PAG; Fig. 2a). In contrast, in three of the seven class 2 neurons tested, vlPAG activation did not significantly alter their response to low-threshold innocuous pressure immediately after PAG activation. Instead, a significant increase in the firing of these neurons was observed 10-15 min post-PAG $\left(n=3, p=0.035, F_{(2,18)}=4.06\right.$, repeated-measures ANOVA followed by Dunnett's post test pre-PAG vs post-PAG; Fig. $2 b$ ). For class 3 neurons $(n=6)$, chemical stimulation of vlPAG significantly reduced their response to noxious pinch by an average of $94.1 \pm 4 \%\left(p=0.0002, F_{(2,22)}=13.04\right.$, repeated-measures ANOVA followed by Dunnett's post test pre-PAG vs PAG; Fig. $2 c)$. For class 4 neurons $(n=8)$, chemical excitation of vlPAG significantly increased their response to joint movement, by an average of $96.1 \pm 23 \%\left(p<0.0001, F_{(2,52)}=13.23\right.$, repeatedmeasures ANOVA followed by Dunnett's post test pre-PAG vs PAG; Fig. 2d). Finally, for class 1 neurons; the response of a single class 1 spino-olivary neuron to innocuous pressure (of three identified) increased by $60 \%$ after chemical stimulation of the vlPAG (Fig. 2e, not discussed further). Histologically recovered sites of microinjection of DLH in the vlPAG are shown in Figure $2 f$.

The results of this first series of experiments therefore provide evidence that the vlPAG influences supraspinal motor systems by differentially modulating sensory signals of different modality that are forwarded to the cerebellum via ascending spino-olivary projections. Transmission of nociceptive signals is reduced, whereas transmission of innocuous and proprioceptive signals is facilitated.

\section{Effects of vlPAG activation on Fos expression in the cerebellar nuclei}

To determine whether the vlPAG can influence cerebellar output, we next assessed the effects of vlPAG stimulation on activity in the cerebellar nuclei, the principal source of output from the cerebellum. Initially, counts of FLI neurons were made in the cerebellar nuclei in two groups: animals mounted in a stereotaxic frame and injected with either (i) saline or (ii) DLH into the vlPAG. The unexpected findings from these initial experiments led us to carry out two additional groups of experiments in which animals were not mounted in a stereotaxic frame: (iii) anesthetic controls and (iv) animals pinched in the trigeminal domain (Fig. 3).

Across all groups, the large majority of FLI neurons in the cerebellar nuclei $(89.0 \pm 10.7 \%$ of total $)$ were located bilaterally in the medial cerebellar nucleus (MCN, in regions related to cerebellar modules A, A2, and AX, $n=32$ ). Because there were no systematic differences between FLI labeling in the left and right cerebellar nuclei, for simplicity, only one side of the cerebellar nuclei is shown in Figure $3 a$. Statistically significant differences were observed between Groups i-iv and nitroprusside control animals $(n=32)$ in the number of FLI neurons in regions of the cerebellar nuclei associated with the A module $\left(F_{(4,27)}=3.46\right.$, $p<0.05$, permutation one-way ANOVA). and the A2 module $\left(F_{(4,27)}=2.86, p<0.05\right)$, but not the AX module $\left(F_{(4,27)}=1.32\right.$, $p>0.05$, see Figure 4 , the latter is not described further).

Surprisingly, the initial experiments revealed that there were significantly more FLI neurons in the $\mathrm{A}(p>0.05, t=2.2, \mathrm{df}=12$ 


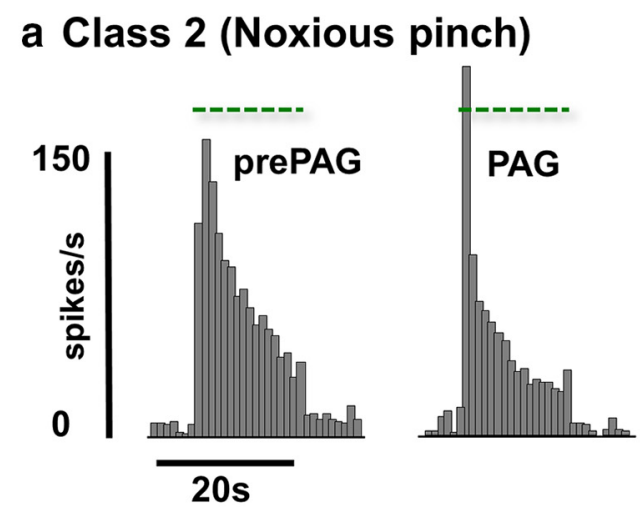

\section{b Class 2 (Innocuous pressure)}

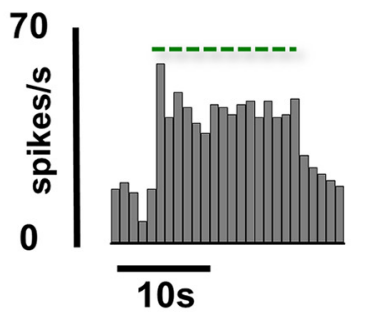

c Class 3 (Noxious pinch)

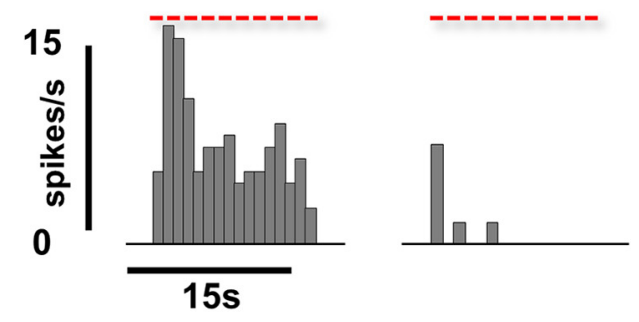

\section{d Class 4 (Proprioceptive)}

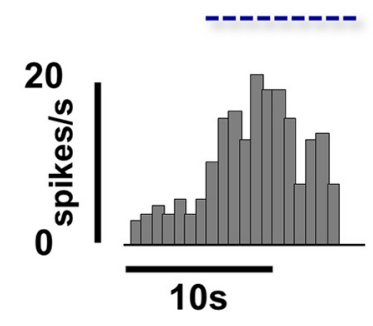

\section{e Class 1}

(Innocuous pressure)

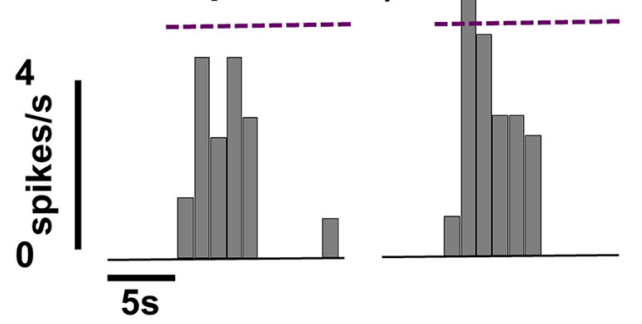

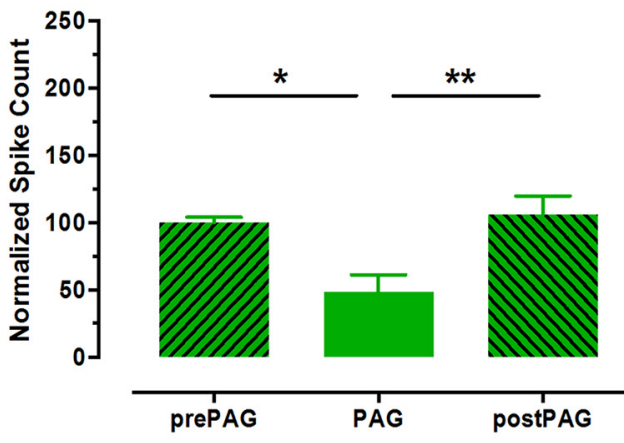
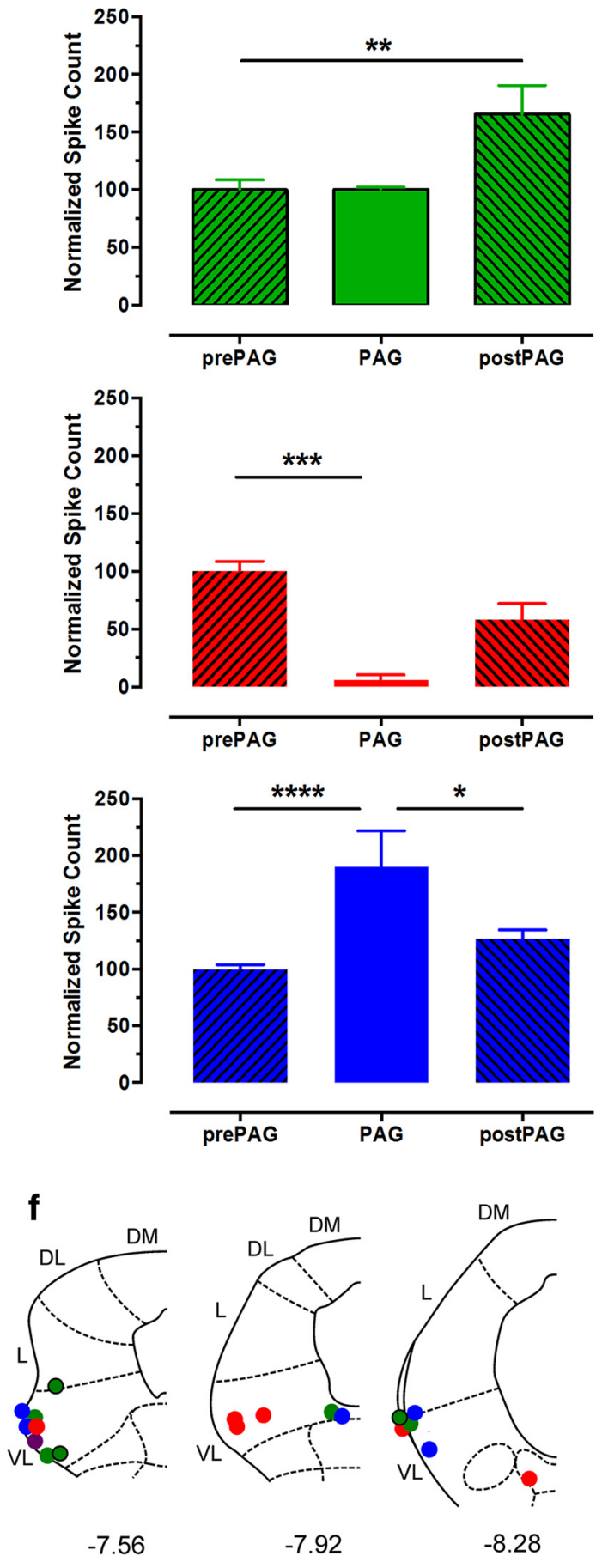

Figure 2. Ventrolateral PAG stimulation selectively alters responses to different qualities of sensory input of spino-olivary projection neurons. $\boldsymbol{a}$, Typical example of the response of a class 2 neuron to noxious pinch $(3.6 \mathrm{~N})$ : peristimulus time histogram (PSTH, spikes per $1 \mathrm{~s}$ bin) are shown before (pre-PAG) and during (PAG) vIPAG chemical excitation. (Figure legend continues.) 
post hoc permutation $t$ test with Bonferroni's correction) and A2 $(p>0.05, t=2.4, \mathrm{df}=12)$ regions of MCN in animals that received saline into the vlPAG (group i, $n=7$ ) compared with those injected with DLH (group ii, $n=7$; Fig. $3 b$ ). In both of these groups, animals were mounted in a stereotaxic frame (with ear bars and a snout clamp), which raised the possibility that the greater number of neurons in saline-treated animals resulted from nociceptive inputs from the trigeminal domain. To test this hypothesis, two additional sets of experiments were performed in animals that were not mounted in a stereotaxic frame; anestheticalone controls (group iii) and animals receiving a noxious stimulus in the trigeminal domain (pinch of the snout) to mimic the stereotaxic procedure (group iv).

Two observations support the view that the high levels of FLI in saline-treated animals did indeed arise from nociceptive input from the head and face: First, in both the A and A2 regions of $\mathrm{MCN}$, there were no significant differences in numbers of FLI neurons between saline-injected and pinched animals [group i vs group iv, $p>0.05, t=0.3(\mathrm{~A}), t=0.9(\mathrm{~A} 2), \mathrm{df}=11]$; and second, in both the $\mathrm{A}$ and $\mathrm{A} 2$ regions, there were significantly more FLI neurons in saline-treated animals compared with anesthetic controls [group I vs group iii, $p<0.05, t=2.4$ (A), $t=2.5$ (A2), $\mathrm{df}=11]$. Further support is also provided by the tendency for there to be more FLI neurons in the A region of MCN in animals that received noxious pinch of the snout compared with anesthetized control animals (group iv vs group iii, mean $273 \pm 147 \%$, $p=0.057, t=2.56, \mathrm{df}=12$, post hoc permutation $t$ test with Bonferroni's correction; Fig. $3 a, b)$.

We therefore interpret these findings to indicate that the increased number of FLI neurons in group i saline-injected and group iv pinched animals compared with group iii anesthetized controls that were not mounted in a stereotaxic head holder was due to nociceptive inputs from the trigeminal domain. If this is the case, then the significant DLH-induced reduction of FLI neurons in the A and $\mathrm{A} 2$ module regions of $\mathrm{MCN}(n=7, \mathrm{~A}$ module region, mean $72 \pm 45 \%$, A2 module region, mean $73 \pm 45 \%$ ) compared with saline-injected animals $[p<0.05, t=2.2(\mathrm{~A}), t=$ 2.4 (A2), $\mathrm{df}=12$, post hoc permutation $t$ test with Bonferroni's correction] most likely reflects a reduction in nociceptor-evoked activity. It should be noted, however, that, although there was an increase in numbers of FLI neurons in the A2 module region in pinch compared with anesthetic controls, this difference was not statistically significant $(p>0.05, t=1.67, \mathrm{df}=12$, post hoc permutation $t$ test with Bonferroni's correction). This may reflect

\footnotetext{
$\leftarrow$

(Figure legend continued.) Dotted horizontal line in each of the PSTHs indicates the onset and duration of the peripheral stimulus. Bar chart shows the average effect of vIPAG stimulation on all class 2 neuronal responses to noxious pinch ( $n=7$ neurons) before (pre-PAG), during (PAG), and after (post-PAG) microinjection of DLH into vIPAG. $\boldsymbol{b}$, Same as $\boldsymbol{a}$ except example class 2 neuron response to innocuous pressure ( $0.5 \mathrm{~N} ; n=3$ neurons). $c$, Same as $\boldsymbol{a}$ except example of class 3 neuron response to noxious pinch ( $3.6 \mathrm{~N} ; n=6$ neurons). $\boldsymbol{d}$, Same as $\boldsymbol{a}$ except example of class 4 neuron response to innocuous ankle joint manipulation ( $n=8$ neurons). All data are expressed as mean \pm SEM of normalized spike counts in response to natural stimuli on the receptive field. ${ }^{*} p<0.05,{ }^{* *} p<0.01,{ }^{* *} p<0.001,{ }^{*{ }^{* *}} p<0.0001$ using repeated-measures ANOVA followed by Dunnett's post test versus pre-PAG. $\boldsymbol{e}$, Example of the response of a single class 1 neuron to innocuous pressure $(0.5 \mathrm{~N})$ : PSTH as described in a.f, Standard transverse maps of the left PAG at three rostrocaudal levels to show histological reconstruction of injection sites in all but three cases in which tissue could be recovered. In every case, the site of injection was verified physiologically with a transient drop in blood pressure in response to microinjection of DLH into vIPAG. Coordinates are relative to bregma. DM, Dorsomedial; DL, dorsolateral; L, lateral; VL, ventrolateral. Purple indicates class 1; green, class 2 (noxious pinch); green with black outline, class 2 (noxious pinch and innocuous pressure); red, class 3; blue, class 4.
}

the intensity of nociceptor stimulation that is required to activate significantly more neurons in this particular module; stereotaxic procedures most likely evoke persistent/inescapable nociceptive inputs compared with pinch of the snout.

It would also be of considerable interest to determine the effects of vlPAG activation on responses in the cerebellar nuclei to proprioceptive stimulation. However, the design of the Fos experiments precluded this because it would have been impossible to produce reproducible synchronized peripheral stimulation and vlPAG stimulation, given the transient effects of PAG chemical stimulation and the nature of the peripheral stimulus: manipulation of the limb.

In sum, the FLI data are consistent with effects of vlPAG action on cerebellar outflow and in agreement with previous studies (Koutsikou et al., 2007): microinjections of DLH into the vlPAG also produced a transient reduction in blood pressure (on average by $16.2 \pm 6.4 \mathrm{mmHg}$ ), whereas microinjections of saline did not produce any detectable change. The locations of microinjections of DLH and saline into the vlPAG were confirmed histologically (Fig. 3c). Two saline and two DLH cases were found to be within $500 \mu \mathrm{m}$ of the lateral border of the vlPAG. However, injections of DLH from these locations produced depressor effects that were indistinguishable from those evoked from within the visible boundaries of the vlPAG.

The changes in blood pressure raise the possibility that the FLI results may be due to autonomic effects. In four animals, the effects of intravenous injection of sodium nitroprusside were therefore also tested at a dose $(100 \mathrm{ng} / \mathrm{ml})$ sufficient to mimic the depressor effects of vlPAG stimulation. In no case did this evoke significant differences in the number of FLI cells in all regions of MCN compared with nonsurgical controls (Fig. 4b).

\section{Characterization of cerebellar field potentials in awake rats}

Having demonstrated in anesthetized animals powerful differential effects of vlPAG activation on the ability of spino-olivary pathways to relay sensory inputs of different modality to the cerebellum and on output from the cerebellar nuclei, we next sought to examine the effect of natural PAG activation in a behavioral setting. To achieve this, we developed a novel stimulation-recording technique that allowed us to monitor, in awake behaving rats, peripherally evoked (hindlimb) CFPs in the copula pyramidis (COP, in the cerebellar cortical component of the $\mathrm{C} 1$ module, termed the $\mathrm{C} 1$ zone; Fig. $5 a, b$ ). We focused our attention on transmission in spinoolivo-cerebellar paths that relay information from hindlimb afferents to the cerebellar $\mathrm{C} 1$ zone because these paths include direct spino-olivary projections that are thought to be especially concerned with the modification of voluntary and reflex limb movements, and because there is extensive knowledge of the anatomy and physiology of this particular cerebellar cortical zone in rats (Atkins and Apps, 1997; Teune et al., 1998; Baker et al., 2001; Pardoe and Apps, 2002; Pijpers et al., 2005; Ackerley et al., 2006; Pijpers et al., 2006).

Consistent with previous results in anesthetized rats (Atkins and Apps, 1997; Cerminara et al., 2009), electrical stimulation of the ipsilateral hindlimb evoked robust CFPs that were localized to specific recording sites within the cerebellar cortex (Fig. $5 a-c$ ). In addition, by simultaneously recording neck EMGs, we were able to demonstrate that these field potentials were not likely to be a far-field muscle response because they increased in amplitude as a function of stimulation intensity that was independent of responses detected in neck EMG. Evoked neck EMG activity was only observed when the stimulus intensity was $>3$ times the threshold to evoke a detectable evoked cerebellar field (for EMG: $p>0.05, F_{(3,27)}=0.90$; for CFPs: $p<0.0001, F_{(3,27)}=52.64$, 


\section{a (i) Saline} (STX)
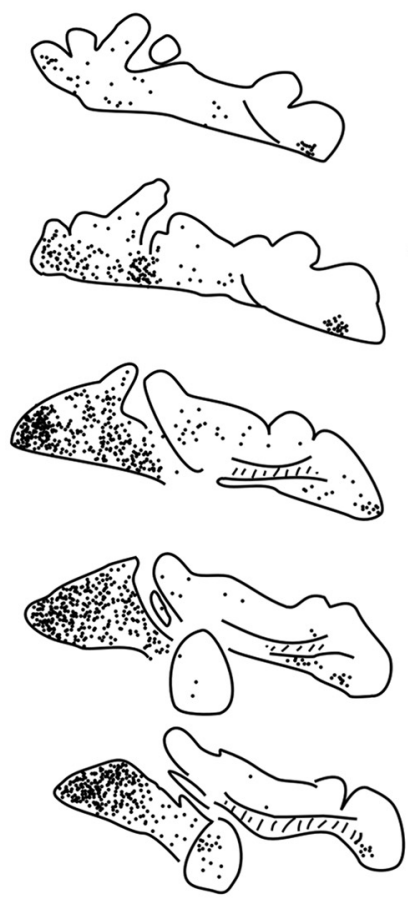

(ii) $D L H$ (STX)
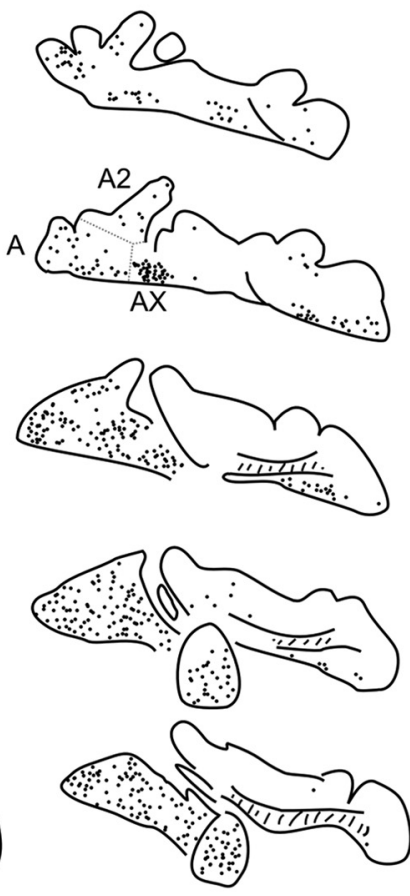

(iii) Anesthetic (no-STX)
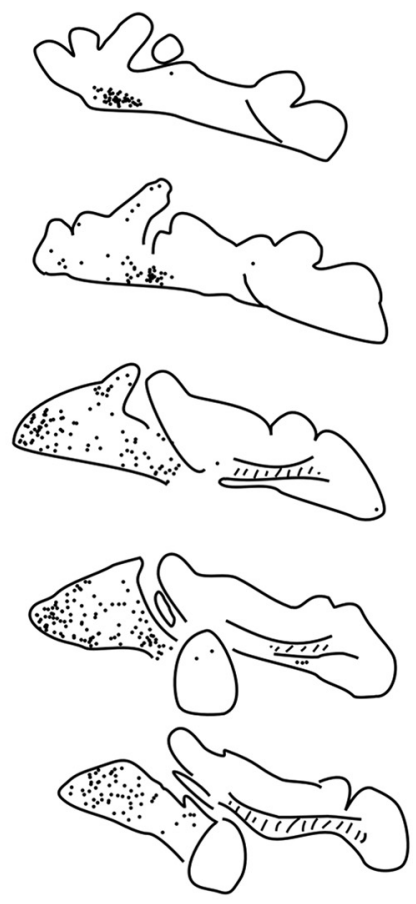

(iv) Noxious pinch (no-STx)
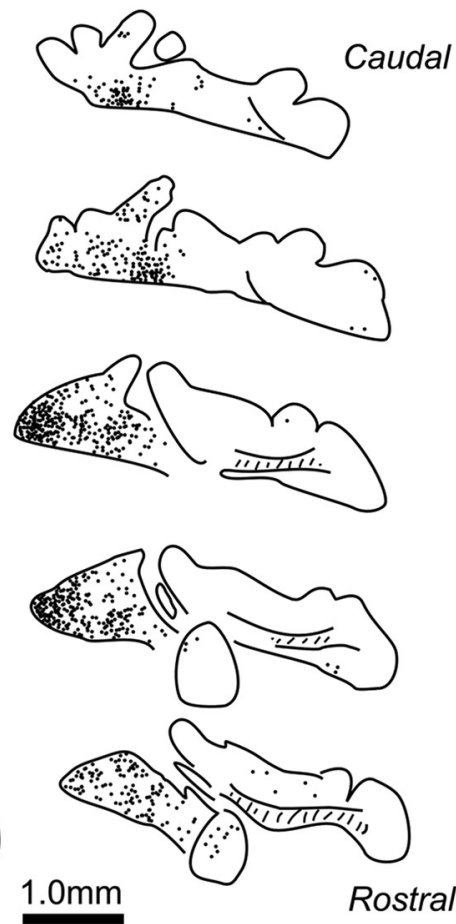

b

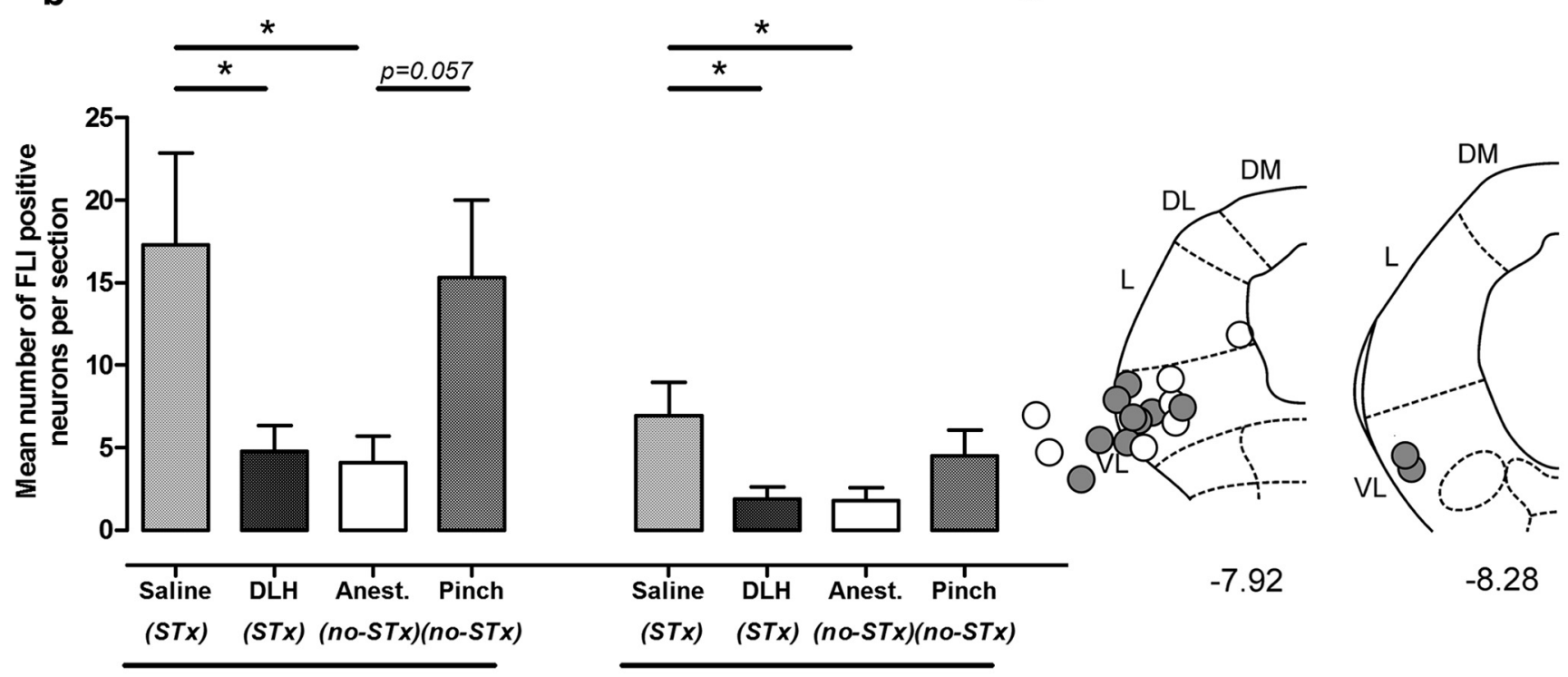

A module

A2 module

Figure 3. Effects of noxious stimulation and vIPAG activation on FLl expression in the A and A2 subdivisions of the cerebellar nuclei. $\boldsymbol{a}$, Standard transverse sections of the right hand cerebellar nuclei showing distribution of FLI neurons for four experimental groups, from left to right: microinjection of (i) saline into vIPAG ( $n=7$ ), (ii) microinjection of DLH into vIPAG ( $n=7$ ), (iii) anesthetic control $(n=8)$, and (iv) noxious pinch of the snout $(n=6)$. Each individual dot represents one FLI neuron. Results from all animals in each group are overlaid, $\boldsymbol{b}$, Mean number of FLI neurons per section in the A and A2 subdivisions for animals in each experimental group. Data are represented as mean \pm SEM. ${ }^{*} p<0.05$, post hoc permutation $t$ test with Bonferroni's correction. $c$, Standard transverse maps of the left PAG at two rostrocaudal levels to show histological reconstruction of injection sites of DLH (filled circles) and saline (open circles). no-STx, No stereotaxy involved in experiment (i.e., no nose clamp or ear bars were used), STx; stereotaxy involved in experiments (i.e., nose clamp and ear bars were used).

repeated-measures ANOVA with Dunnett's post test vs baseline, $n=7$ rats, Fig. $5 d$ ).

Consistent with previous studies (Atkins and Apps, 1997; Teune et al., 1998; Jörntell et al., 2000; Baker et al., 2001; Pardoe and Apps, 2002), individual cerebellar recording sites were iden- tified as being located within the hindlimb-receiving part of the $\mathrm{C} 1$ zone in COP by their location in the medial part of the paravermal cortex and by the presence of CFPs evoked by lowintensity electrical stimulation of the ipsilateral hindlimb (Fig. $5 c$ ). During implant surgery under sodium pentobarbital anes- 
a

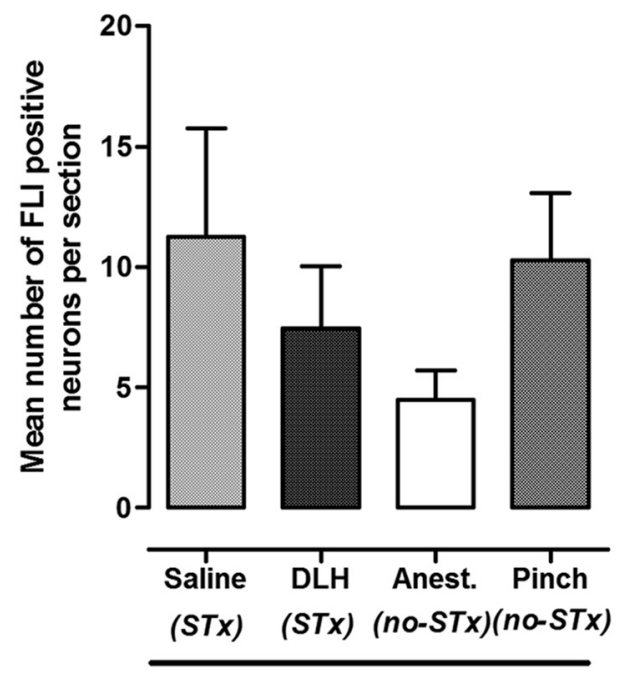

AX module b

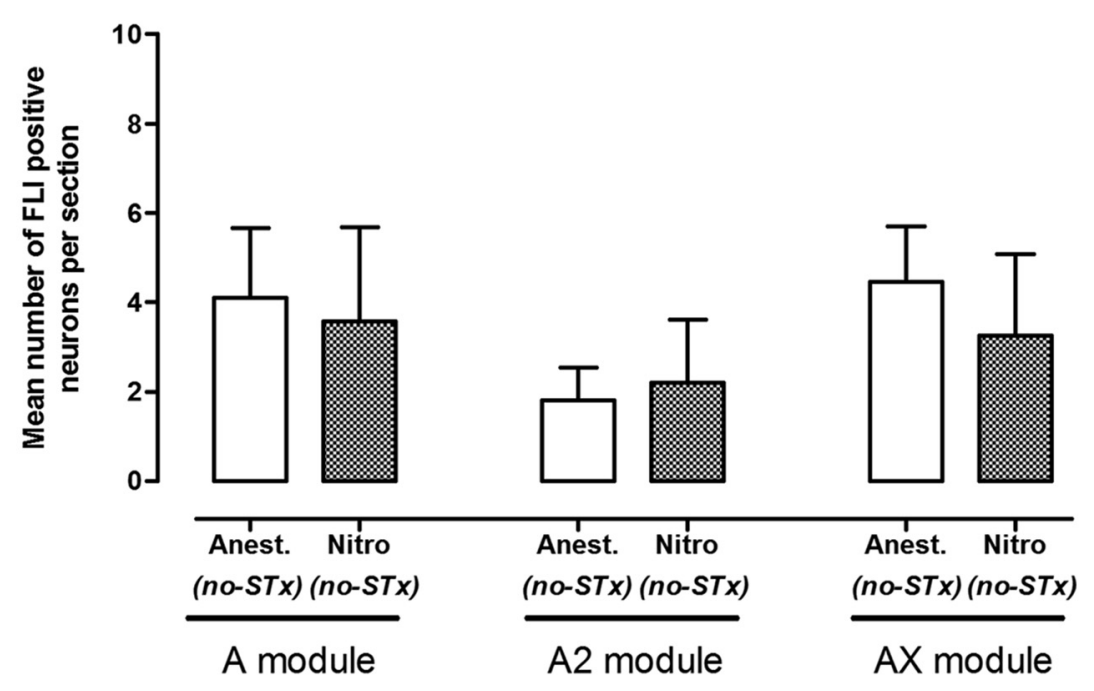

Figure 4. Effects of noxious stimulation and VIPAG activation on FLI expression in the AX subdivision of the cerebellar nuclei and control experiments with nitroprusside. $\boldsymbol{a}$, Mean number of FLI neurons per section in the AX subdivision of the MCN for animals in each experimental group. No statistically significant differences were observed in the groups with microinjection of saline into VIPAG $(n=7)$, microinjection of DLH into vIPAG $(n=7)$, anesthetic control $(n=8)$, and noxious pinch of the snout $(n=6, p>0.05$, permutation one-way ANOVA). $\boldsymbol{b}$, Mean number of FLI neurons per section in different subdivisions of MCN for anesthetic control (Anesth) and nitroprusside (Nitro) control groups. No significant differences in FLI in the MCN were observed between animals administered with sodium nitroprusside $(n=4)$ and anesthetic control animals $(n=8, p>0.05$, permutation one-way ANOVA).

thesia, the onset latency of these CFPs was $16 \pm 0.1 \mathrm{~ms}$ with latency to peak of $19.5 \pm 1.0 \mathrm{~ms}(n=7 \mathrm{rats})$. These latency measurements are in good agreement with previous studies in anesthetized rats (Atkins and Apps, 1997). However, in the awake animal, the onset latency of responses recorded at the same recording sites consistently shifted significantly earlier to an onset of $12.5 \pm 0.1 \mathrm{~ms}$ and peak of $15.9 \pm 0.5 \mathrm{~ms}$, respectively; $(p<$ $0.001, t=5.8, \mathrm{df}=6$, paired $t$ test, $n=7$ rats). No systematic difference was evident between onset latency of individual CFPs and recording position in $\operatorname{COP}\left(p>0.05, F_{(2,11)}=0.29\right.$, one-way ANOVA with Bonferroni's post test, $n=14$ rats).

The CFPs displayed the following features typical of climbing fiber (CF) field potentials: (1) an onset latency that was always $>10 \mathrm{~ms}$ (spino-cerebellar mossy fiber responses have shorter latencies), (2) a highly characteristic waveform with a duration of $\sim 5 \mathrm{~ms}$ that was always shorter than responses attributable to activity in longer latency mossy fiber paths (Kennedy et al., 1966; Morissette and Bower, 1996), (3) trial-by-trial fluctuations in response size, and (4) a pattern of response to a paired pulse test that was typical of CF responses. When two supramaximal stimuli were delivered at interstimulus intervals ranging from 30 to $60 \mathrm{~ms}$, the second response always exhibited a reduction in size (Eccles et al., 1966; Armstrong and Harvey, 1968); $n=$ 7 rats; Fig. 5e, red dashed line). An initial shorter latency response (presumably related to mossy fiber inputs) was also sometimes present, which had an onset latency of $6.0 \pm 0.3 \mathrm{~ms}$ $(n=14)$. These earlier responses displayed no change in amplitude to a paired pulse test and were not studied further (Fig. $5 e$, black dashed line).

Additional evidence that the longer latency CFPs were CF in origin was obtained in six animals in which we recorded single Purkinje cell activity at the same cerebellar cortical recording sites where the largest field potentials were evoked. In every case, complex spike activity was evoked at a latency similar to that of the field potentials $(13.1 \pm 1.4 \mathrm{~ms} ; n=6$; Fig. $5 f)$.
Together, these data therefore suggest that the longer latency CFPs recorded in the awake animal were mainly CF in origin.

Having characterized the hindlimb evoked CFPs as mainly, if not exclusively, CF in origin (and therefore relayed via spinoolivocerebellar paths, SOCPs), we were in a position to examine the effect of artificial (DLH-evoked) and natural (fear-evoked) activation of the vlPAG on their amplitude. First, in one awake rat sitting quietly at rest in its home cage, we injected DLH via an indwelling bilateral cannula to chemically activate the vlPAG while electrically stimulating at regular intervals the ipsilateral hindlimb at low intensity $(1.5 \times$ threshold for a detectable CFP; every $1.5 \mathrm{~s}$; see Materials and Methods for further details). As a result, we were able to monitor any changes in CFP amplitude and thus any modulation of SOCP transmission in the awake animal before, during, and after direct chemical activation of vlPAG neurons. After injection of DLH (Fig. $6 a$, dotted vertical line), the animal displayed a marked increase in freezing-like behavior from a baseline of 50\% at rest pre-DLH (Fig. $6 a$, left light gray horizontal bar) to $95 \%$ freezing-like behavior (Fig. $6 a$, black bar). Concomitant with the increase in freezing-like behavior, evoked CFPs decreased in amplitude by $\sim 30 \%$ (from $0.48 \pm$ $0.02 \mathrm{mV}$ to $0.34 \pm 0.01 \mathrm{mV}$ ) and then, over a period of $\sim 500 \mathrm{~s}$, slowly returned to baseline levels as freezing-like behavior subsided ( $0.49 \pm 0.01 \mathrm{mV}$; Fig. $6 a$, right light gray bar). Postmortem histology confirmed the location of the cannulae within vlPAG (Fig. 6b).

\section{CF fields are reduced during freezing behavior}

Although the results obtained from a single animal should be considered with caution, these data are nevertheless proof of principle that SOCP transmission can be reduced by vlPAG activation in the awake animal. This is in full agreement with more detailed analysis previously obtained under anesthesia 

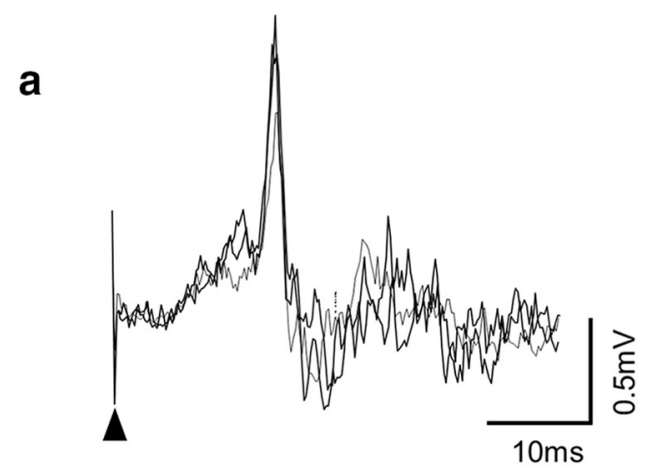

C
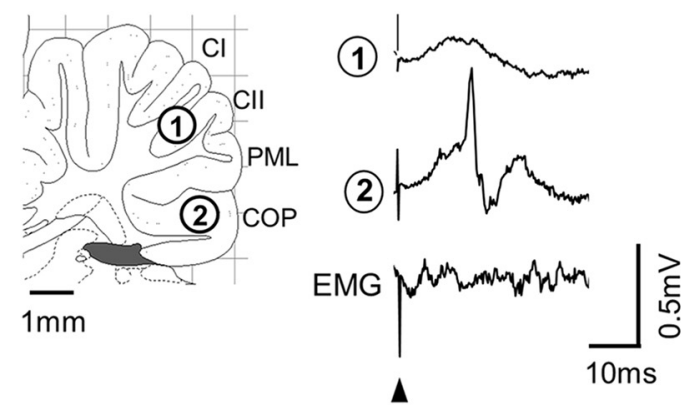

e

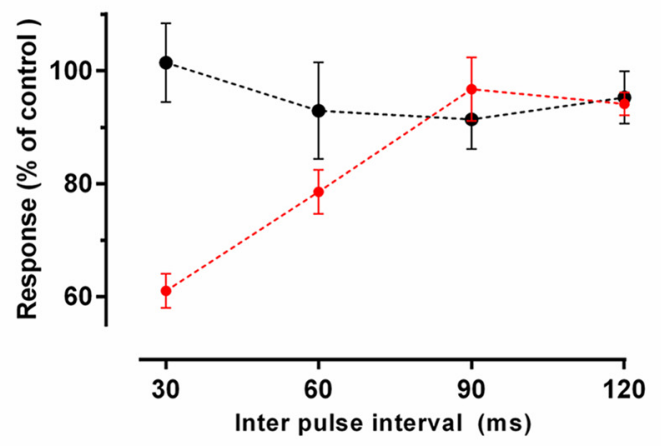

b

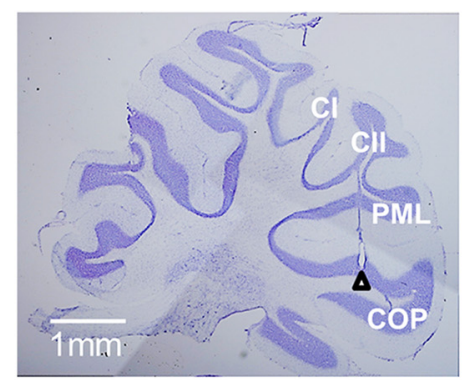

d

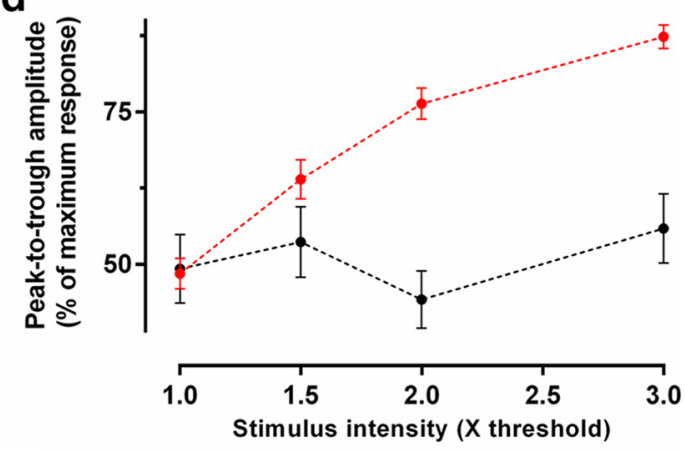

f

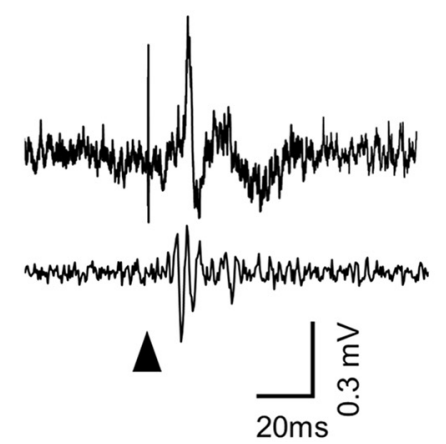

Figure 5. Characterization of hindlimb evoked CFPs in awake rat. $\boldsymbol{a}$, Superimposition of 3 consecutive field potentials evoked by electrical stimulation of the ipsilateral hindlimb (1.5 $\times$ threshold) in an awake rat (stimulus onset indicated by filled arrowhead). $\boldsymbol{b}$, Sagittal section of cerebellum showing electrode position (lesion indicated by filled arrowhead) from which recordings shown in $\boldsymbol{a}$ were made. c, Top two traces, Example average field potential waveforms (10 consecutive trials) recorded simultaneously from two positions shown in the sagittal section of the cerebellum. Bottom trace, Simultaneously recorded neck EMG. $\boldsymbol{d}$, Stimulus-response curve for CFPs (red dashed line) and EMG (black dashed line) after ipsilateral hindlimb stimulation ( $n=7$ rats). Stimulus intensity is expressed as multiples of the threshold (T) required to evoke a detectable cerebellar response. $\boldsymbol{e}$, Effect of paired hindlimb stimulation on the amplitude of the early (black dashed line) and late component (red dashed line) of evoked CFPs recorded in COP ( $n=7$ rats). $f$, Example CFP (top trace) and individual Purkinje cell complex spike (bottom trace) evoked by ipsilateral hindlimb stimulation (filled arrowhead) recorded from the same position in $\mathrm{COP}$ in one rat. $\mathrm{COP}$, copula pyramidis; $\mathrm{Cl}$, crus I; Cll, crus Il; PML, paramedian lobule.

(Cerminara et al., 2009). As a result, we went on to examine the effects on SOCP transmission of behaviorally more relevant activation of vlPAG. Using a fear-conditioning paradigm, which is known to activate neurons in the vlPAG (Carrive et al., 1997), we examined the effects on SOCP transmission during freezing (Fig. $6 c$ ). Because SOCPs are known to be gated during movement (Lidierth and Apps, 1990; Apps and Lee, 1999; Apps, 1999; Apps, 2000), we restricted our comparison of evoked CFP amplitude to periods of quiescence (animals at rest in their home cage displaying no movement) and periods of conditioned freezing (in response to a previously conditioned auditory tone, CS).

During CS-evoked freezing, the amplitude of CFPs was moderately but statistically significantly decreased compared with responses recorded during quiescence (on average, CFP amplitude reduced by $20 \pm 2 \%, p<0.001, t=8.8, \mathrm{df}=4$, paired $t$ test, $n=$ 5; Fig. $6 c$ ). To identify freezing epochs, we also recorded neck EMG during behavior (Steenland and Zhuo, 2009). Concomitant with the decrease in CFP amplitude, there was also a tonic increase in neck EMG amplitude during freezing epochs compared with quiescence (average increase of $25 \pm 7 \% p<0.05, t=3.8$, $\mathrm{df}=4$, paired $t$ test; $n=5$ animals; Fig. $6 d$ ).

Together with our previous work (Cerminara et al., 2009; Koutsikou et al., 2014), these results suggest that, under certain conditions, vlPAG can both decrease excitability in SOCPs and at the same time increase excitability in spinal motor circuits. Given that similar phenomena would seem to be present in both awake and anesthetized preparations, our final set of experiments explored whether this differential modulation by the vlPAG can occur simultaneously. 
a

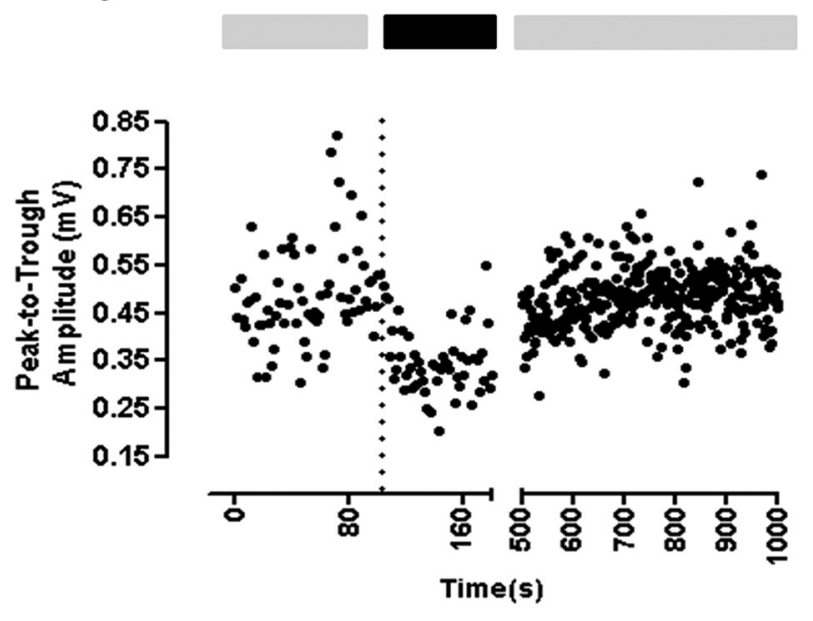

b
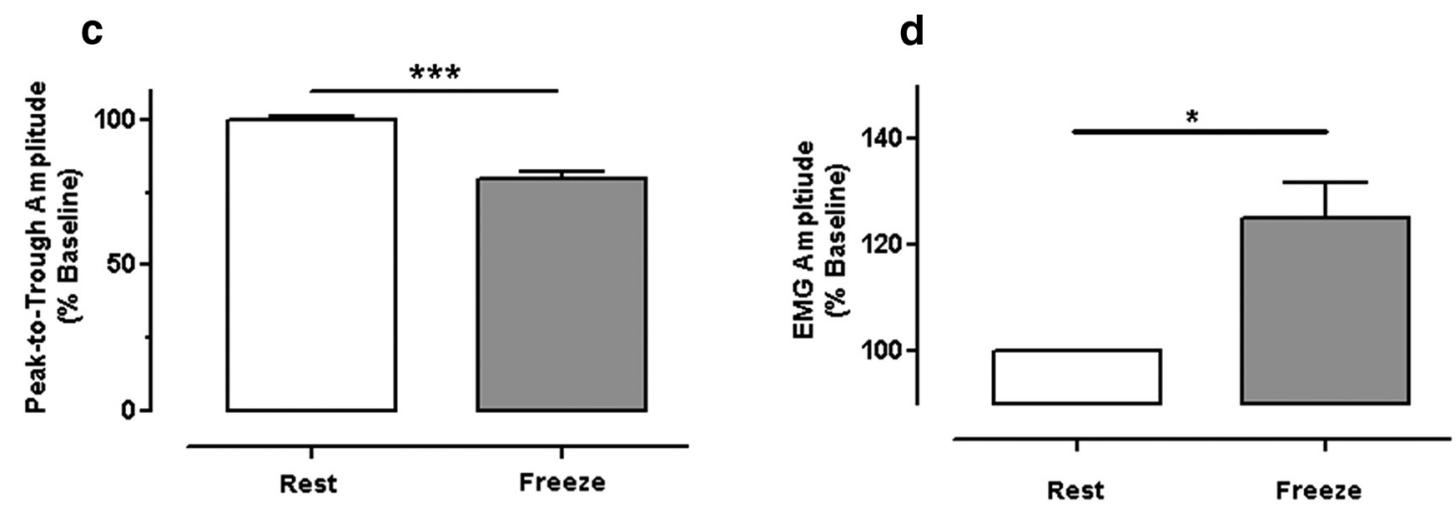

Figure 6. Evidence of modulation in olivocerebellar pathway transmission during freezing. $\boldsymbol{a}$, In one animal, the excitatory amino acid DLH was injected ( $100 \mathrm{nl}, 50 \mathrm{~mm}$; dashed line indicates time of injection) into the vIPAG while recording CFP responses evoked by ipsilateral hindlimb stimulation. DLH injection resulted in a reduction in (FP amplitude, together with a robust expression of freezing-like behavior (horizontal black bar indicates period in which the rat spent $95 \%$ of time in freezing-like behavior; light gray bars indicate baseline (55\%) and recovery (52\%) levels of inactivity, respectively). $\boldsymbol{b}$, Camera lucida drawing of transverse view of PAG ( $-8.16 \mathrm{~mm}$ relative to bregma) showing location of bilateral injection cannulae (indicated by filled areas). $\boldsymbol{c}$, Group data from fear conditioning experiments in which the amplitude of evoked CFPs was measured during periods of spontaneous inactivity (open bar, before fear recall) and during identified freezing epochs (filled bar, after exposure to previously conditioned stimuli). ${ }^{* * *} p<0.001$, paired $t$ test $; n=5$ rats. $\boldsymbol{d}$, EMG amplitude during the same conditions as in $\mathbf{c}\left({ }^{*} p<0.05\right.$, paired $t$ test; $n=5$ rats). dm, Dorsomedial PAG; lat, lateral PAG; dl, dorsolateral PAG.

\section{Simultaneous gating of SOCPs and modulation of motor outflow}

To determine whether neurons in the vlPAG can simultaneously gate sensory transmission to supraspinal motor systems (cerebellar evoked responses) and modulate spinal motor outflow ( $\alpha$ motoneuron excitability), DLH was microinjected into the vlPAG of anesthetized rats and recordings were made simultaneously of CFP and spinal H-reflex responses. Figure $7 a$ illustrates typical examples of averaged raw data from a single experiment. Low-intensity electrical stimulation of the tibial nerve evoked CFPs in the ipsilateral COP (C1 zone; Fig. 7ai) and H-reflex responses in the ipsilateral hindlimb (Fig. 7aii). In this case, microinjection of DLH in vlPAG caused a transient abolition of the CFP (pre-PAG vs PAG; Fig. 7ai) while simultaneously increasing the amplitude of the H-reflex response relative to baseline response size (pre-PAG vs PAG; Fig. 7aii). On average, neuronal activation of vlPAG significantly decreased the amplitude of the CFP by $89.8 \pm 1 \%\left(n=5, p<0.0001, F_{(2,72)}=92.46\right.$, repeated-measures ANOVA followed by Dunnett's post test vs pre-PAG; Fig. 7b, hatched bars) and significantly increased the peak-to-peak amplitude of the H-reflex, as indicated by an increase in the H:M ratio of $38.8 \pm 0.4 \%(n=5, p=0.0025$, $F_{(2,72)}=10.45$, repeated-measures ANOVA followed by Dun- nett's post test vs pre-PAG; Fig. $7 b$, open bars). Both the CFP and H-reflex responses returned to baseline levels within a 2-10 min period after vlPAG activation. Postmortem histological reconstruction confirmed that the microinjections of DLH were all located within vlPAG $(n=5$; Fig. $7 c)$.

The effects of vlPAG on dorsal horn neurons described in the first part of this study may affect motoneuronal output at a spinal segmental level. For example, projection neurons in the dorsal horn, which may be subject to descending control, have been shown to have collateral projections to the ventral horn (Szucs et al., 2010). Nonetheless, the concurrent monitoring of CFPs and $\mathrm{H}$ reflex responses provides strong evidence that vlPAG can orchestrate differential changes in ascending sensorimotor projections and spinal motor systems simultaneously.

\section{Discussion}

Despite the fundamental importance of motor behaviors evoked from the PAG, including freezing coordinated by its ventrolateral sector, virtually nothing is known of the underlying neural pathways and mechanisms. The current study has provided novel insights into this issue. Importantly, we show that modulation of $\alpha$-motoneuronal output and fear-evoked freezing behavior can occur simultaneously with modulation 


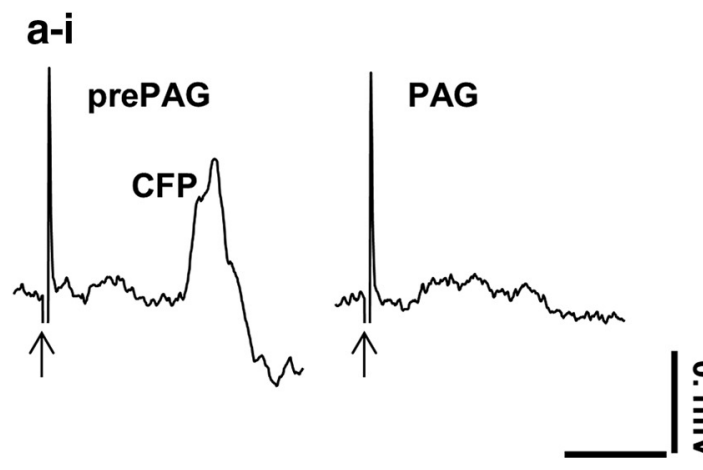

$10 \mathrm{~ms}$

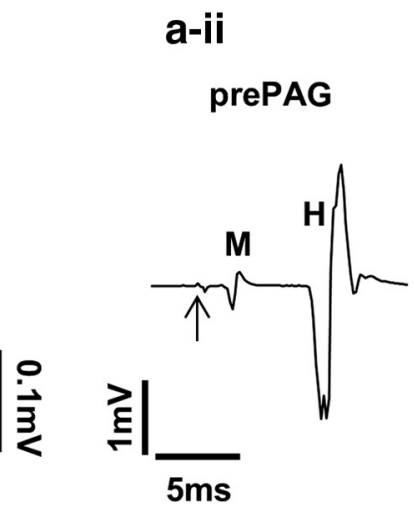

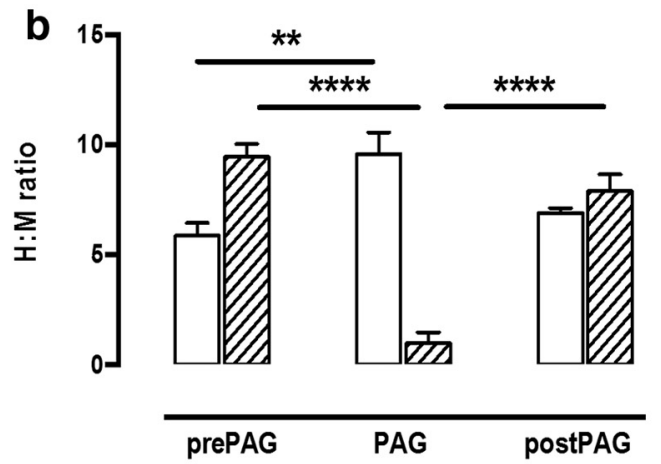

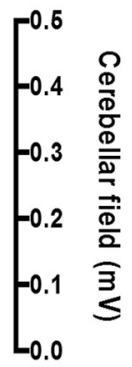

C
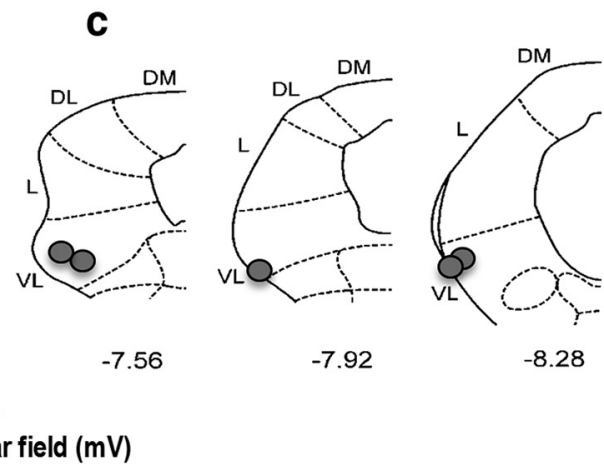

$\square$ H:M ratio

[D Cerebellar field (mV)

$-7.92$

$-8.28$

Figure 7. Activation of vIPAG results in simultaneous, differential modulation of SOCP transmission and spinal reflex circuits. ai, Example CFPs recorded from the surface of the cerebellar cortex ( $(1$ zone of left copula pyramidis). aii, Examples of averaged $\mathrm{M}$-wave $(\mathrm{M})$ and $\mathrm{H}$-reflex $(\mathrm{H})$ responses recorded from the left plantaris muscle at the same time as ai. All responses were evoked by electrical stimulation of the ipsilateral tibial nerve $(<1 \mathrm{~mA})$. Each example consists of five consecutive responses averaged before (pre-PAG) and during (PAG) vIPAG chemical excitation with DLH. Arrows indicate onset of the electrical stimulus. $\boldsymbol{b}$, Group data (mean \pm SEM) showing that microinjections of DLH into the vIPAG facilitate the mean $\mathrm{H}$-reflex amplitude expressed relative to the size of the M-wave (H:M ratio) during (PAG) vIPAG neuronal activation (open bars; left $y$-axis; $n=5,{ }^{* *} p=0.0025, F_{(2,72)}=10.45$, repeated-measures ANOVA followed by Dunnett's post test vs pre-PAG). Simultaneously, vIPAG excitation reduces (FP responses evoked by the same electrical stimulus (hatched bars; right $y$-axis; $n=5,{ }^{* * * *} p<0.0001, F_{(2,72)}=92.46$, repeated-measures ANOVA followed by Dunnett's post test vs pre-PAG). c, Standard transverse maps of the left PAG to show location of injection sites of DLH in the vIPAG (filled circles). Coordinates are relative to bregma. DM, Dorsomedial; DL, dorsolateral; L, lateral; VL, ventrolateral.

of SOCPs, presumably in a coordinated way and perhaps reflecting a common spinal mechanism.

\section{Effects of vlPAG on spinal processing in precerebellar pathways}

This is the first description in the rat of the physiological characteristics of spino-olivary neurons. As detailed in the Materials and Methods, neurons were classified by their responses to cutaneous (noxious and non-noxious) and proprioceptive (limb manipulation) inputs. The proportions of spino-olivary neurons in each class are similar to those described for unidentified (nonprojection) deep dorsal horn neurons (Waters and Lumb, 1997; McMullan and Lumb, 2006b; Waters and Lumb, 2008), including cells of origin of the spinothalamic tract (Chung et al., 1979). Spino-olivary projections are relayed via the ventral funiculus SOCP, which involves a number of subpaths that target cerebellar modules including the A, A2, and AX zones in the vermis and the hindlimb $\mathrm{C} 1$ zone in the paravermis (Oscarsson and Sjolund, 1977). The present characterization of dorsal horn activity and evoked CFPs in response to vlPAG activation therefore included transmission in the same general category of ascending pathways. These paths are thought to forward information to the cerebellum about activity in segmental reflex circuits. In terms of projections to the A modules, such signals are presumably concerned with the control of balance and the postural base for voluntary movements, including eye and head movements (Cerminara and Apps, 2011), whereas signals forwarded to the hindlimb compo- nent of the $\mathrm{C} 1$ module may be involved in the adaptive control of peripherally evoked reflexes during locomotion (Lidierth and Apps, 1990; Apps et al., 1995; Pijpers et al., 2008).

Our dorsal horn recordings of spino-olivary projection neurons provide evidence that descending control arising from the PAG selectively reduces transmission in spino-olivary paths of acutely generated nociceptive signals. This selective control of cutaneous input is consistent with previous studies of descending control of dorsal horn cells (Heinricher et al., 2009), including those that project supraspinally, such as spinothalamic tract neurons. This raises the possibility that the spino-olivary tract may consist, at least in part, of collaterals of the spinothalamic tract. However, there is no direct evidence for this and our previous anatomical pathway tracing studies indicate that this is unlikely to be the case (Flavell et al., 2014).

Our dorsal horn recordings also found that transmission of non-noxious, proprioceptive (presumably mainly group I afferent) signals is enhanced, a novel finding with important implications. From a behavioral perspective, it has been proposed that, in active and passive defense scenarios, when the PAG is engaged, such selectivity would depress nociceptive input that could distract an animal from carrying out behaviors necessary for survival and leave intact non-noxious information that provides precise information with the capacity to direct motor activity to promote survival (Lumb, 2004). We have reported previously that descending control of spinal transmission of non-nociceptive information of cutaneous origin may be facilitated by the PAG 
(Waters and Lumb, 2008) and other sites (Workman and Lumb, 1997; Simpson et al., 2008). Our finding that vlPAG can also facilitate proprioceptive input to precerebellar pathways provides a mechanism whereby information from spinal circuits involved in monitoring limb position and movement can be enhanced, thus refining sensory input that directs motor control. Such an effect is entirely consistent with a role for the PAG in coordinating motor behaviors in defense situations.

However, enhancement of transmission of proprioceptive signals via spino-olivary projections would seem to conflict with our additional finding that transmission of low-threshold sensory signals is reduced in SOCPs targeting the hindlimb $\mathrm{C} 1$ zone in COP. This apparent discrepancy may be explained by previous studies in decerebrate and pentobarbitone-anesthetized cats, in which transmission of group I proprioceptive signals in SOCPs arising from hindlimb nerves was weak and arose from specific ipsilateral hindlimb nerves, notably quadriceps and gastrocnemus-soleus nerves, and was relayed only when these nerves were stimulated repetitively (Armstrong et al., 1968; Oscarsson, 1968). The stimulus location and parameters used in the present experiments to evoke activity in SOCPs electrically may therefore have been insufficient to activate group I afferents relayed via this route. In addition, although considerable convergence from nerves subserving different modalities is a consistent feature of the CF system, cerebellar zones can nonetheless differ in their pattern of afferent input. For example, the $\mathrm{C} 1$ zone receives nociceptive cutaneous afferents, whereas the neighboring C2 zone does not (Garwicz et al., 1992). This raises the possibility that proprioceptive afferents are directed to specific parts of the cerebellar cortex not studied in the present experiments (e.g., hindlimb receiving areas in the anterior lobe or vermis). In addition, more generalized suppression of sensory input might result from a contribution of supraspinal sites, as indicated by our previous findings (Cerminara et al., 2009), in addition to spinal gating, as described in the present study.

The present study also provides evidence for a strong nociceptive drive to neurons in the MCN. MCN has extensive connections with brainstem structures (Teune et al., 2000), including cells of origin of motor pathways that regulate head movements, posture, and proximal limb movements (Ito, 1984). Activation in the vlPAG caused a reduction in the numbers of FLI neurons in response to nociceptor stimulation that was restricted to regions of MCN associated with the A and A2 modules. These regions of MCN have a complex pattern of projections to numerous brainstem structures, including the vestibular nuclei, medial reticular formation, and superior colliculus (Teune et al., 2000). Activation of these circuits by noxious peripheral stimuli could therefore result in adjustments in orientation and body posture that might compromise appropriate motor responses in a fearful situation. The present data indicate that activation of the vlPAG depresses nociceptor-evoked response in the MCN and, as a consequence, this could enhance survival by limiting the impact of nociceptive input on the execution of motor responses in fearful situations.

\section{Coordinated effects on sensorimotor systems}

In two separate lines of enquiry, one in anesthetized and one in awake animals, we provide evidence that the vlPAG has the capacity to coordinate effects on motor behavior together with transmission in SOCPs, as assessed by monitoring changes in CFPs to electrical stimulation of the ipsilateral hindlimb. The data are consistent with our previous report in anesthetized rats (Cerminara et al., 2009) showing that vlPAG activation causes a reduction in transmission in SOCPs, but the present study extends this to show that this is closely linked to freezing behavior.

We have previously reported facilitation of $\alpha$-motoneuronal activity from vlPAG as measured by an increase in H-reflex excitability (Koutsikou et al., 2014) and have suggested that this effect might contribute to the role of the PAG in freezing, which involves a generalized and sustained increase in muscle tone. Together with our current results in both anesthetized and awake animals, this suggests that localized pools of neurons in the vlPAG simultaneously coordinate effects on sensory transmission in SOCPs and on motor outflow. The underlying neural circuits remain to be fully characterized. However, it may be relevant to note that direct connections exist between the vlPAG and the IO (Rutherford et al., 1984; Holstege, 1988; Van Bockstaele et al., 1991; Watson et al., 2013) and such a projection may play a role in gating SOCP transmission, although it should be emphasized that the modulation could occur via other indirect pathways. With regard to vlPAG influence on spinal reflex circuits, our previous studies have shown that this is dependent on a transcerebellar circuit involving vermal lobule VIII (the pyramis; Koutsikou et al., 2014).

\section{Functional significance}

We suggest that the differential gating of nociceptive cutaneous and proprioceptive information to the cerebellum by the vlPAG, together with the enhancement of motor outflow, may contribute to the generation of appropriate motor responses associated with freezing behavior. More specifically, the engagement of coordinated influences from the vlPAG promotes a condition in which the animal is ready (enhanced proprioceptive input and increased muscle activity, thus promoting directed active coping behavior; Walker and Carrive, 2003) and able to escape (less likely to be perturbed by noxious sensory information), thus assisting survival.

\section{References}

Ackerley R, Pardoe J, Apps R (2006) A novel site of synaptic relay for climbing fibre pathways relaying signals from the motor cortex to the cerebellar cortical C1 zone. J Physiol 576:503-518. CrossRef Medline

Apps R (1999) Movement-related gating of climbing fibre input to cerebellar cortical zones. Prog Neurobiol 57:537-562. CrossRef Medline

Apps R (2000) Gating of climbing fibre input to cerebellar cortical zones. Prog Brain Res 124:201-211. CrossRef Medline

Apps R, Lee S (1999) Gating of transmission in climbing fibre paths to cerebellar cortical $\mathrm{C} 1$ and $\mathrm{C} 3$ zones in the rostral paramedian lobule during locomotion in the cat. J Physiol 516:875-883. CrossRef Medline

Apps R, Hartell NA, Armstrong DM (1995) Step phase-related excitability changes in spino-olivocerebellar paths to the $\mathrm{c} 1$ and $\mathrm{c} 3$ zones in cat cerebellum. J Physiol 483:687-702. CrossRef Medline

Armstrong DM, Harvey RJ (1968) Responses to a spino-olivo-cerebellar pathway in the cat. J Physiol 194:147-168. CrossRef Medline

Armstrong DM, Eccles JC, Harvey RJ, Matthews PB (1968) Responses in the dorsal accessory olive of the cat to stimulation of hind limb afferents. J Physiol 194:125-145. CrossRef Medline

Atkins MJ, Apps R (1997) Somatotopical organisation within the climbing fibre projection to the paramedian lobule and copula pyramidis of the rat cerebellum. J Comp Neurol 389:249-263. Medline

Azizi SA, Woodward DJ (1987) Inferior olivary nuclear complex of the rat: morphology and comments on the principles of organization within the olivocerebellar system. J Comp Neurol 263:467-484. CrossRef Medline

Baker MR, Javid M, Edgley SA (2001) Activation of cerebellar climbing fibres to rat cerebellar posterior lobe from motor cortical output pathways. J Physiol 536:825-839. CrossRef Medline

Blanchard RJ, Blanchard DC (1969) Crouching as an index of fear. J Comp Physiol Psychol 67:370-375. CrossRef Medline

Buisseret-Delmas C (1988) Sagittal organization of the olivocerebellonu- 
clear pathway in the rat. I. Connections with the nucleus fastigii and the nucleus vestibularis lateralis. Neurosci Res 5:475-493. CrossRef Medline

Buisseret-Delmas C, Angaut P (1993) The cerebellar olivo-corticonuclear connections in the rat. Prog Neurobiol 40:63-87. CrossRef Medline

Carrive P, Leung P, Harris J, Paxinos G (1997) Conditioned fear to context is associated with increased Fos expression in the caudal ventrolateral region of the midbrain periaqueductal gray. Neuroscience 78:165-177. CrossRef Medline

Cerminara NL, Apps R (2011) Behavioural significance of cerebellar modules. Cerebellum 10:484-494. CrossRef Medline

Cerminara NL, Koutsikou S, Lumb BM, Apps R (2009) The periaqueductal grey modulates sensory input to the cerebellum: a role in coping behaviour? The Eur J Neurosci 29:2197-2206. CrossRef Medline

Chen XY, Wolpaw JR (2005) Ablation of cerebellar nuclei prevents H-reflex down-conditioning in rats. Learn Mem 12:248-254. CrossRef Medline

Chung JM, Kenshalo DR Jr, Gerhart KD, Willis WD (1979) Excitation of primate spinothalamic neurons by cutaneous C-fiber volleys. J Neurophysiol 42:1354-1369. Medline

Eccles JC, Llinás R, Sasaki K (1966) The excitatory synaptic action of climbing fibres on the purinje cells of the cerebellum. J Physiol 182:268-296. CrossRef Medline

Flavell CR, Cerminara NL, Apps R, Lumb BM (2014) Spino-olivary projections in the rat are anatomically separate from postsynaptic dorsal column projections. J Comp Neurol 522:2179-2190. CrossRef Medline

Fuller JH, Schlag JD (1976) Determination of antidromic excitation by the collision test: problems of interpretation. Brain Res 112:283-298. CrossRef Medline

Garwicz M, Ekerot CF, Schouenborg J (1992) Distribution of cutaneous nociceptive and tactile climbing fibre input to sagittal zones in cat cerebellar anterior lobe. Eur J Neurosci 4:289-295. CrossRef Medline

Gozariu M, Roth V, Keime F, Le Bars D, Willer JC (1998) An electrophysiological investigation into the monosynaptic $\mathrm{H}$-reflex in the rat. Brain Res 782:343-347. CrossRef Medline

Hartell NA, Headley PM (1990) Spinal effects of four injectable anaesthetics on nociceptive reflexes in rats: a comparison of electrophysiological and behavioural measurements. Br J Pharmacol 101:563-568. CrossRef Medline

Heinricher MM, Tavares I, Leith JL, Lumb BM (2009) Descending control of nociception: Specificity, recruitment and plasticity. Brain Res Rev 60: 214-225. CrossRef Medline

Holstege G (1988) Brainstem-spinal cord projections in the cat, related to control of head and axial movements. Rev Oculomot Res 2:431-470. Medline

Hunt SP, Pini A, Evan G (1987) Induction of c-fos-like protein in spinal cord neurons following sensory stimulation. Nature 328:632-634. CrossRef Medline

Ito M (1984) Cerebellum and neural control. New York: Raven.

Ito M (2001) Cerebellar long-term depression: characterization, signal transduction, and functional roles. Physiol Rev 81:1143-1195. Medline

Jörntell H, Ekerot C, Garwicz M, Luo XL (2000) Functional organization of climbing fibre projection to the cerebellar anterior lobe of the rat. J Physiol 522:297-309. CrossRef Medline

Kennedy TT, Grimm RJ, Towe AL (1966) The role of cerebral cortex in evoked somatosensory activity in cat cerebellum. Exp Neurol 14:13-32. CrossRef Medline

Koutsikou S, Parry DM, MacMillan FM, Lumb BM (2007) Laminar organization of spinal dorsal horn neurones activated by C- vs. A-heat nociceptors and their descending control from the periaqueductal grey in the rat. Eur J Neurosci 26:943-952. CrossRef Medline

Koutsikou S, Crook JJ, Earl EV, Leith JL, Watson TC, Lumb BM, Apps R (2014) Neural substrates underlying fear-evoked freezing: the periaqueductal grey-cerebellar link. J Physiol 592:2197-2213. CrossRef Medline

LaFleur BJ, Greevy RA (2009) Introduction to permutation and resampling-based hypothesis tests. J Clin Child Adolesc Psychol 38:286-294. CrossRef Medline

LeDoux J (2012) Rethinking the emotional brain. Neuron 73:653-676. CrossRef Medline

LeDoux JE, Iwata J, Cicchetti P, Reis DJ (1988) Different projections of the central amygdaloid nucleus mediate autonomic and behavioral correlates of conditioned fear. J Neurosci 8:2517-2529. Medline

Leith JL, Koutsikou S, Lumb BM, Apps R (2010) Spinal processing of noxious and innocuous cold information: differential modulation by the periaqueductal gray. J Neurosci 30:4933-4942. CrossRef Medline

Lidierth M, Apps R (1990) Gating in the spino-olivocerebellar pathways to the $\mathrm{cl}$ zone of the cerebellar cortex during locomotion in the cat. J Physiol 430:453-469. CrossRef Medline
Lipski J (1981) Antidromic activation of neurones as an analytic tool in the study of the central nervous system. J Neurosci Methods 4:1-32. CrossRef Medline

Llinás RR (2011) Cerebellar motor learning versus cerebellar motor timing: the climbing fibre story. J Physiol 589:3423-3432. CrossRef Medline

Lovick TA, Bandler R (2005) The organisation of the midbrain periaqueductal grey and the integration of pain behaviours In: The neurobiology of pain (Hunt SP, Koltzenburg M, eds), pp 267-287. Oxford: OUP.

Lumb BM (2004) Hypothalamic and midbrain circuitry that distinguishes between escapable and inescapable pain. News Physiol Sci 19:22-26. Medline

Mattsson JL, Albee RR, Brandt LM (1984) H-reflex waveform and latency variability in rats. Fundam Appl Toxicol 4:944-948. CrossRef Medline

McMullan S, Lumb BM (2006a) Midbrain control of spinal nociception discriminates between responses evoked by myelinated and unmyelinated heat nociceptors in the rat. Pain 124:59-68. CrossRef Medline

McMullan S, Lumb BM (2006b) Spinal dorsal horn neuronal responses to myelinated versus unmyelinated heat nociceptors and their modulation by activation of the periaqueductal grey in the rat. J Physiol 576:547-556. CrossRef Medline

Menétrey D, Giesler GJ Jr, Besson JM (1977) An analysis of response properties of spinal cord dorsal horn neurones to nonnoxious and noxious stimuli in the spinal rat. Exp Brain Res 27:15-33. Medline

Merrill EG, Ainsworth A (1972) Glass-coated platinum-plated tungsten microelectrodes. Med Biol Eng 10:662-672. CrossRef Medline

Molinari HH, Dostrovsky JO (1987) Functional properties of neurons in the cat gracile nucleus that project to the dorsal accessory olive. Exp Brain Res 69:119-130. Medline

Morissette J, Bower JM (1996) Contribution of somatosensory cortex to responses in the rat cerebellar granule cell layer following peripheral tactile stimulation. Exp Brain Res 109:240-250. Medline

Oscarsson O (1968) Termination and functional organization of the ventral spino-olivocerebellar path. J Physiol 196:453-478. CrossRef Medline

Oscarsson O, Sjölund B (1977) The ventral spino-olivocerebellar system in the cat. III. Functional characteristics of the five paths. Exp Brain Res 28:505-520. Medline

Pardoe J, Apps R (2002) Structure-function relations of two somatotopically corresponding regions of the rat cerebellar cortex: olivo-corticonuclear connections. Cerebellum 1:165-184. CrossRef Medline

Pardoe J, Edgley SA, Drew T, Apps R (2004) Changes in excitability of ascending and descending inputs to cerebellar climbing fibers during locomotion. J Neurosci 24:2656-2666. CrossRef Medline

Franklin K, Paxinos G (2005) The mouse brain in stereotaxic coordinates, Ed 5. Burlington, MA: Elsevier.

Pijpers A, Voogd J, Ruigrok TJ (2005) Topography of olivo-cortico-nuclear modules in the intermediate cerebellum of the rat. J Comp Neurol 492: 193-213. CrossRef Medline

Pijpers A, Apps R, Pardoe J, Voogd J, Ruigrok TJ (2006) Precise spatial relationships between mossy fibers and climbing fibers in rat cerebellar cortical zones. J Neurosci 26:12067-12080. CrossRef Medline

Pijpers A, Winkelman BH, Bronsing R, Ruigrok TJ (2008) Selective impairment of the cerebellar $\mathrm{C} 1$ module involved in rat hind limb control reduces step-dependent modulation of cutaneous reflexes. J Neurosci 28 : 2179-2189. CrossRef Medline

Ruigrok TJ, Voogd J (1990) Cerebellar nucleo-olivary projections in the rat: an anterograde tracing study with Phaseolus vulgaris-leucoagglutinin (PHA-L). J Comp Neurol 298:315-333. CrossRef Medline

Ruigrok TJ, Voogd J (2000) Organization of projections from the inferior olive to the cerebellar nuclei in the rat. J Comp Neurol 426:209-228. CrossRef Medline

Rutherford JG, Anderson WA, Gwyn DG (1984) A reevaluation of midbrain and diencephalic projections to the inferior olive in rat with particular reference to the rubro-olivary pathway. J Comp Neurol 229:285-300. CrossRef Medline

Sacchetti B, Scelfo B, Tempia F, Strata P (2004) Long-term synaptic changes induced in the cerebellar cortex by fear conditioning. Neuron 42:973982. CrossRef Medline

Simpson DA, Headley PM, Lumb BM (2008) Selective inhibition from the anterior hypothalamus of C- versus A-fibre mediated spinal nociception. Pain 136:305-312. CrossRef Medline

Steenland HW, Zhuo M (2009) Neck electromyography is an effective measure of fear behavior. J Neurosci Methods 177:355-360. CrossRef Medline 
Szucs P, Luz LL, Lima D, Safronov BV (2010) Local axon collaterals of lamina I projection neurons in the spinal cord of young rats. J Comp Neurol 518:2645-2665. Medline

Teune TM, van der Burg J, de Zeeuw CI, Voogd J, Ruigrok TJ (1998) Single Purkinje cell can innervate multiple classes of projection neurons in the cerebellar nuclei of the rat: a light microscopic and ultrastructural tripletracer study in the rat. J Comp Neurol 392:164-178. CrossRef Medline

Teune TM, van der Burg J, van der Moer J, Voogd J, Ruigrok TJ (2000) Topography of cerebellar nuclear projections to the brain stem in the rat. Prog Brain Res 124:141-172. Medline

Van Bockstaele EJ, Aston-Jones G, Pieribone VA, Ennis M, Shipley MT (1991) Subregions of the periaqueductal gray topographically innervate the rostral ventral medulla in the rat. J Comp Neurol 309:305-327. CrossRef Medline

Walker P, Carrive P (2003) Role of ventrolateral periaqueductal gray neurons in the behavioral and cardiovascular responses to contextual conditioned fear and poststress recovery. Neuroscience 116:897-912. CrossRef Medline

Waters AJ, Lumb BM (1997) Inhibitory effects evoked from both the lateral and ventrolateral periaqueductal grey are selective for the nociceptive responses of rat dorsal horn neurones. Brain Res 752:239-249. CrossRef Medline

Waters AJ, Lumb BM (2008) Descending control of spinal nociception from the periaqueductal grey distinguishes between neurons with and without C-fibre inputs. Pain 134:32-40. CrossRef Medline

Watson TC, Koutsikou S, Cerminara NL, Flavell CR, Crook JJ, Lumb BM, Apps R (2013) The olivo-cerebellar system and its relationship to survival circuits. Front Neural Circuits 7:72. Medline

Workman BJ, Lumb BM (1997) Inhibitory effects evoked from the anterior hypothalamus are selective for the nociceptive responses of dorsal horn neurons with high- and low-threshold inputs. J Neurophysiol 77:28312835. Medline 